CHARACTER MEDIATION OF PLOT STRUCTURE: TOWARD AN EMBODIED MODEL OF NARRATIVE 


\title{
CHARACTER MEDIATION OF PLOT STRUCTURE: TOWARD AN EMBODIED MODEL OF NARRATIVE
}

\author{
By CARMEN TU, B.H.Sc.
}

A Thesis Submitted to the School of Graduate Studies in Partial Fulfilment of the Requirements for the Degree Master of Science

McMaster University C Copyright by Carmen Tu, August 2019 
McMaster University MASTER OF SCIENCE (2019) Hamilton, Ontario (Psychology, Neuroscience \& Behaviour)

TITLE: Character mediation of plot structure: Toward an embodied model of narrative AUTHOR: Carmen Tu, B.H.Sc. (McMaster University)

SUPERVISOR: Professor S. Brown

NUMBER OF PAGES: ix, 54 


\section{Lay Abstract}

The classic view of narrative since the time of Aristotle is that plot structure is prioritized over characters in defining the nature of stories. According to this view, plot is external to the protagonist, and the protagonist's actions are determined by the end goals of the plot. The current analysis calls for a reversal in the prioritization of these elements in creating a story. We present an Embodied Plot model in which character not only drives plot, but in essence represents the plot as well. According to this model, the psychological processes occurring in the protagonist's mind construct the dramatic arc of plot. Plot structure is thus akin to the problem-solving experience of the protagonist inside the storyworld. We apply this model to a number of fairy tales to demonstrate how the dramatic arc of these stories can be explained in each case by the protagonist's experience in the story. 


\begin{abstract}
The classic view of narrative since the time of Aristotle is that plot structure is prioritized over characters in defining the nature of stories. According to this view, plot is an abstract structure external to the protagonist, and the protagonist's actions are determined by the thematic goals of the plot. The current analysis calls for a reversal in the prioritization of these elements in creating a story. We present an Embodied Plot model in which character not only drives plot, but embodies plot as well. According to this model, the dramatic arc of plots is attributable to psychological processes occurring in the protagonist's mind. Plot structure is thus isomorphic with the psychological and problemsolving experience of the protagonist inside the storyworld. We apply this model to a number of fairy tales to demonstrate how the dramatic arc of these stories can be explained in each case by the protagonist's experientiality.
\end{abstract}




\section{Acknowledgements}

I would like to express my gratitude to Dr. Steven Brown for his support and encouragement over these past two years. Thank you, Steven, for all your patience, guidance, and opportunities you have given me. I'm lucky to be a student in your lab and to have you as a devoted supervisor. You help make the work interesting, exciting, and inspiring. I have grown a lot as a researcher and scholar under your supervision.

Thank you to my colleagues and friends in the NeuroArts lab who warmly

welcomed me with opened arms from day one and have been the sturdy social and emotional pillars of my graduate experience. Matt, you are such a thoughtful mentor and I am grateful for your all of your brotherly advice. Kiran, you bring so much life and love wherever you go, day or night, and I am thankful to have shared my graduate experience with you.

I would like to thank my parents, whom I don't thank enough. Thank you for your support in everything I do, even when it is not always easy. Thank you for your love, your acceptance, and the home that you have given me. 


\section{Table of Contents}

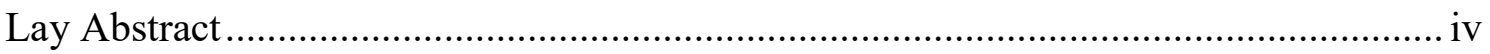

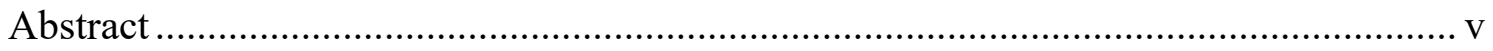

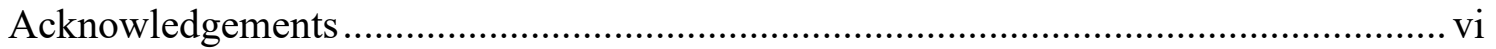

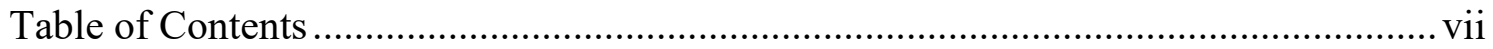

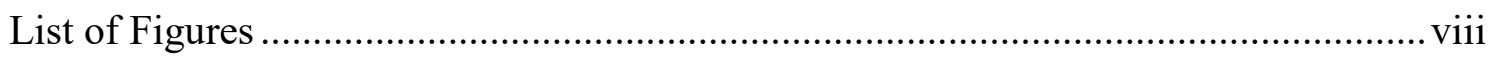

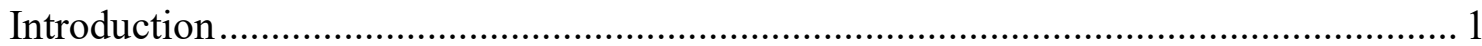

Plot-Driven vs. Character-Driven Models of Plot Structure................................ 2

Historical Models of Plot Structure …........................................................... 5

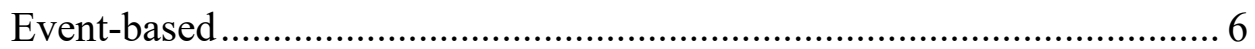

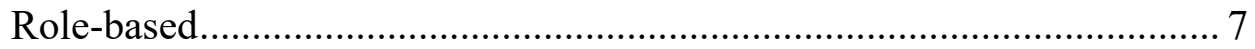

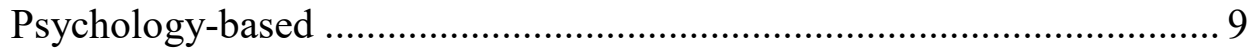

The Embodied Plot Model ........................................................................................ 14

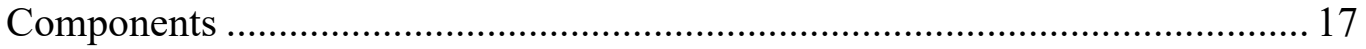

The Constituents of Plot Structure ............................................................... 29

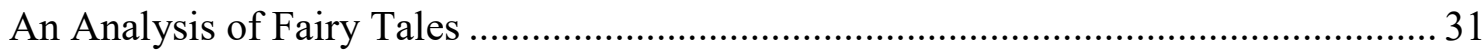

Jack and the Beanstalk ................................................................................. 32

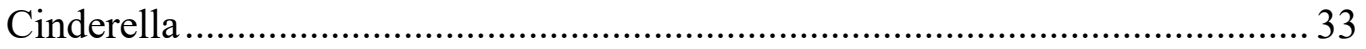

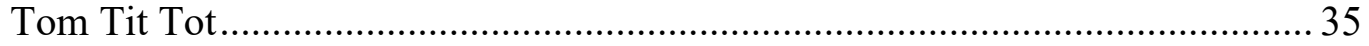

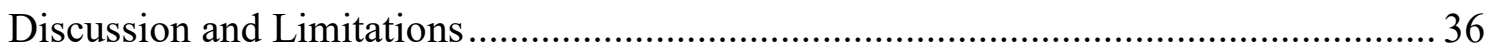

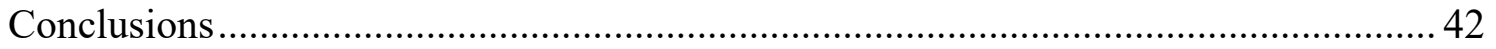

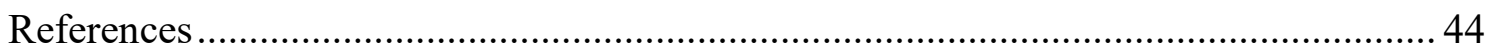




\section{List of Figures}

Figure 1: Plot-based vs. Character-based Conceptions of the Relationship Between Plot and Characters In Stories ......................................................................... 4

Figure 2: A Typology of Plot Models Based on the Extent to which they are Plot-driven

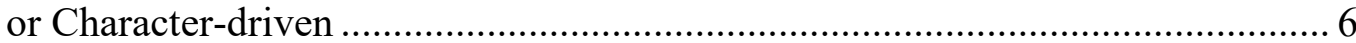

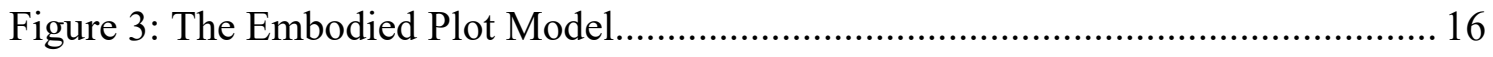

Figure 4: The Basic Constituents of Plot According to the

Embodied Plot Model ............................................................................... 31

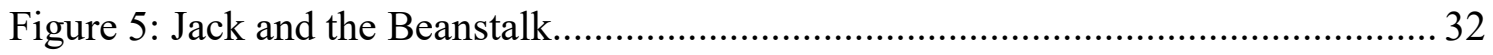

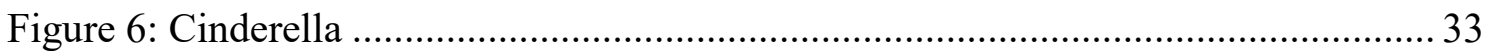

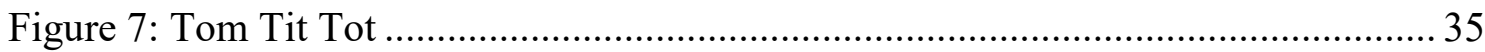




\section{Declaration of Academic Achievement}

The original theory and research presented in this thesis was developed by myself in collaboration with my supervisor Dr. Steven Brown. I conducted the literature review, devised the model in conjunction with Dr. Steven Brown, and analyzed the sample corpus of short fairy tales. The work presented in this manuscript is in preparation to be submitted for publication in a journal as a paper. 
M.Sc. Thesis - C. Tu; McMaster University - Psychology, Neuroscience \& Behaviour

\section{Introduction}

Most literary theorists agree that plot and character are the two essential elements of a story (Abbott, 2008). A plot without characters would simply be a series of events, and a character without a plot would simply be a profile of a person. It is therefore the combination of people and happenings that makes something into a story in most cases. Perspectives on the relationship between plot and character vary quite strongly within narrative theory, where some theories prioritize plot over character, and others character over plot. In what is perhaps the earliest exposition of literary theory, Aristotle (335 BCE/1996) presented a model of narrative in Poetics which fundamentally prioritized plot over character. Aristotle argued that character is secondary to plot, since "character is included along with and on account of the actions. So the events, i.e. the plot, are what tragedy is there for, and that is the most important thing of all" (Aristotle, 335 BCE/1996, p.11). Due to Aristotle's influence, plot-centered approaches to narrative have predominated for much of the last two thousand years. For example, the structural narratologists of the $20^{\text {th }}$ century adopted an event-based perspective in which a story is seen primarily as a sequence of causally-linked episodes (Bal, 1985/2017; Genette, 1982; Prince, 1982; Ricoeur, 1980; Ryan, 2007). In the current paper, we will present a new model of plot structure that we call the Embodied Plot model that attempts to unite plot and character in a manner that has not been proposed in previous models. In particular, we will argue that not only does character drive the structure of a plot, but it defines it as well. By this view, plot structure is seen to be isomorphic with the psychological experience of the protagonist inside the storyworld, and the dramatic arc of plots is attributable to psychological processes occurring in the protagonist's mind. This will comprise an extreme example of a character-driven model, one in which character actually subsumes plot. 
M.Sc. Thesis - C. Tu; McMaster University - Psychology, Neuroscience \& Behaviour

\section{Plot-driven vs. character-driven models of plot structure}

Before we present the details of the Embodied Plot model, we will discuss a proposed relationship between plot and character in narrative theory, first in an abstract manner (this section) and then through an analysis of historical narrative theories (the next section). Narrative structure can be described in a purely episode-based and plot-driven manner or in a manner that additionally incorporates the psychology and experientiality of characters (Fludernik, 1996). Figure 1 presents a conceptual analysis of two idealized but contrastive views of the relationship between plot and character, as shown graphically in the two comic scenarios. This analysis will serve as a theoretical guide for the next section, which will discuss historical models of plot structure in relation to whether they are either plot-driven or character-driven. For now, we will discuss this as an abstract distinction between the two notions that "plot drives character" (panel A) and "character drives plot" (panel B) as nearly opposite manners of conceiving of the relationship between plot and character in stories.

A plot-driven model of story structure attributes the progression and causal structure of a narrative to external storyworld factors, not to the agency of characters. The character is a passive element in such a model, being driven by forces external to him- or herself, for example the prophesy of the oracle in Oedipus Rex. The plot-driven scenario in Figure 1A shows the storyworld as providing all of the necessary resources for the person to complete their task. The person effortlessly fills the barrel with water provided through a faucet hose. They are then transported over the obstacle of the rugged mountain along a fixed path to their final destination by means of a pulley system that is operated by an omnipotent external force. The pulley system is a metaphor for the plot that is operating on and controlling the character along the track towards the final outcome. The track represents the fixed episodic progression of the plot 
M.Sc. Thesis - C. Tu; McMaster University - Psychology, Neuroscience \& Behaviour

sequence, which the character passively follows. This type of approach to modelling plot is akin to Aristotle's (335 BCE/1996) three-act structure, in which characters are viewed as merely populating the plot, rather than driving it and are subject to godly manipulations. Culler (1980) describes a character who conforms to the demands of the plot as being a "tropological construct", which refers to any narrative concept or element that is defined by thematic tropes or archetypes. Culler gives the example of Oedipus, whose story Culler claims is largely attributed to Oedipus's requirement to fulfill his destiny. He argues that "Oedipus's slaying of Laius is not something given as reality but is produced by a tropological operation, the result of narrative requirements" (p. 30). Oedipus is a tropological construct since he is the vehicle for realizing the story's tragedy trope; his choices and actions are dictated by a prophecy. To use a linguistic analogy, Oedipus is the patient of the plot, not its agent. 
M.Sc. Thesis - C. Tu; McMaster University - Psychology, Neuroscience \& Behaviour

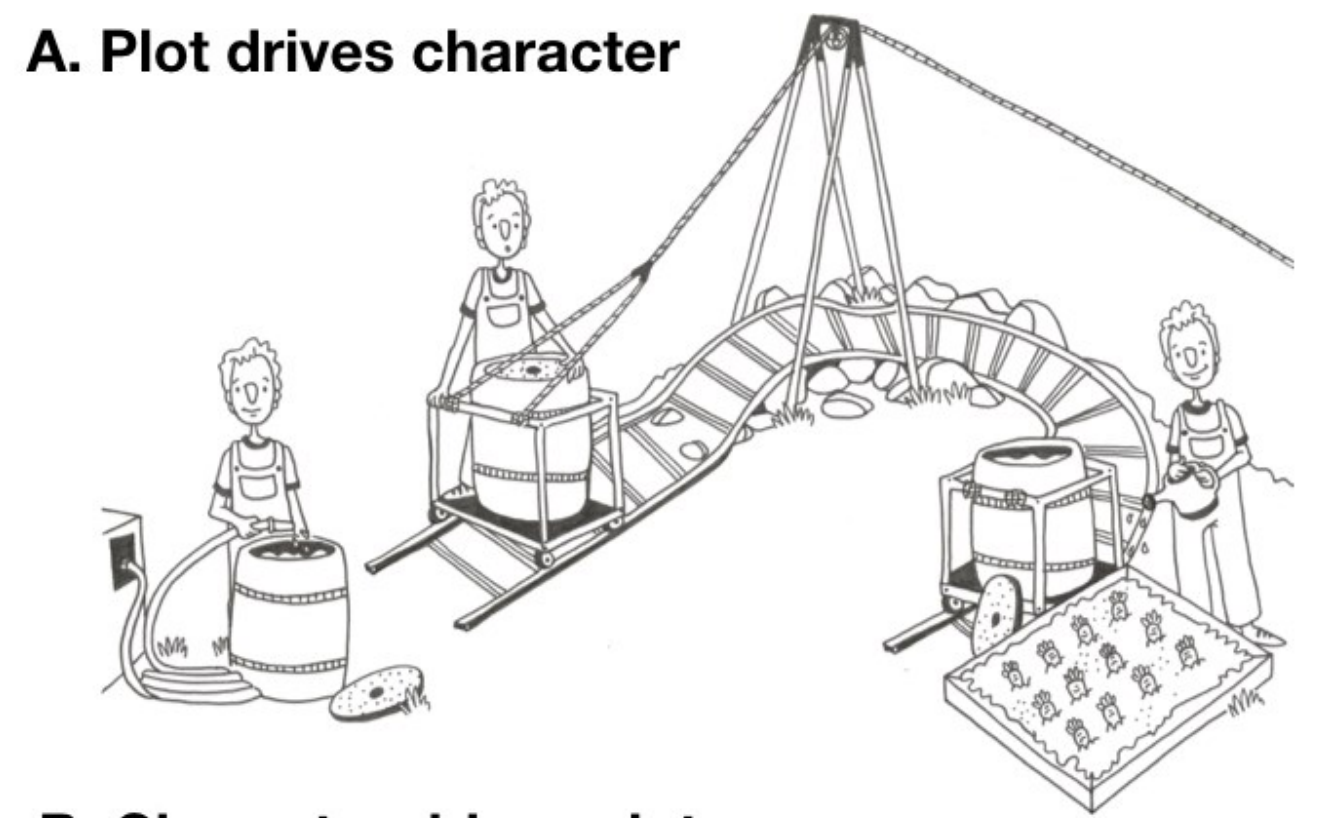

B. Character drives plot

Figure 1. Two contrastive conceptions of the relationship between plot and character in stories. In A, the plot is the major determinant of the story's events, and the character simply moves along the fixed path specified by the plot. In B, the path of the story's events is determined by the emotions, agency, and problem-solving dynamics of the protagonist, whose actions become the plot itself. In this scenario, the protagonist sets out his own path, and expends much effort toward overcoming obstacles in order to achieve a consequential goal.

In a character-driven model of plot structure, by contrast, the character is now an active agent and is thus the major determinant of the progression of the plot. Narrative causality is attributed to character psychology. The scenario in Figure 1B shows the protagonist as having goals, making choices, reacting to his choices, and exerting effort in order to achieve his goals. 
M.Sc. Thesis - C. Tu; McMaster University - Psychology, Neuroscience \& Behaviour

With pained effort, he forges his own path to overcome the obstacle of the rugged mountain to reach the other side of the mountain and thereby achieve a consequential goal related to sustenance. He chooses to climb over the mountain instead of using another method, such as digging through or under the mountain. This is the key contrast between a plot-driven approach and a character-driven approach: a plot-driven model describes the plot as pulling the character, while a character-driven model describes the character as pushing the plot forward. In the character-driven model, the dramatic arc of the plot structure is essentially isomorphic with the psychological reactions of the protagonist during the process of seeking a consequential outcome.

\section{Historical models of plot structure}

Having presented abstract models of these two extreme cases, we can now examine published models of plot structure with regard to where they sit in between these extremes. In Figure 2, the plot models are shown to extend from plot-driven to character-driven, as indicated by the spectrum on the left side of the figure using images from Figure 1. We propose that plot models span from what we will call event-based to role-based to psychology-based models, as shown on the right side of Figure 2. 
M.Sc. Thesis - C. Tu; McMaster University - Psychology, Neuroscience \& Behaviour

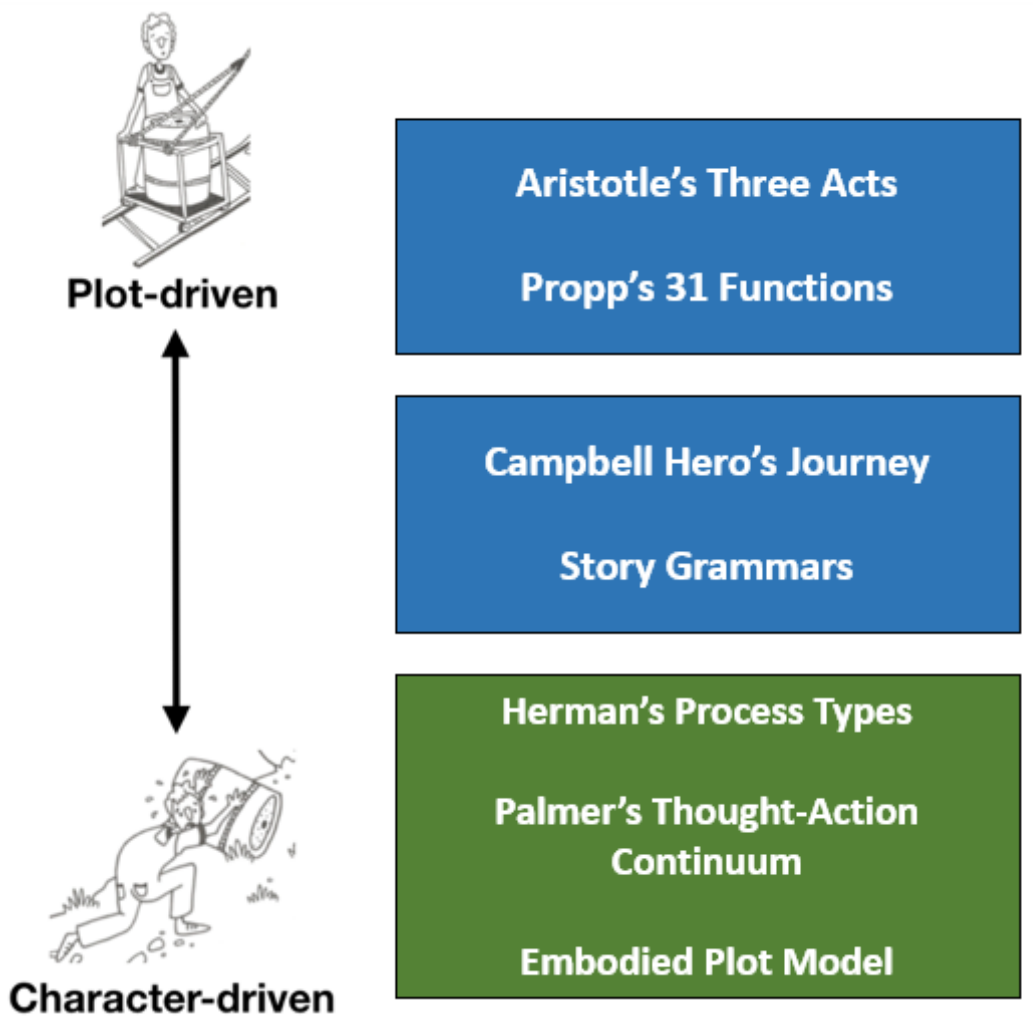

\section{Event-based}

Describes event progression

\section{Role-based}

Describes protagonist actions and outcomes

\section{Psychology-based}

Explains protagonist intentions and agency

Figure 2. A typology of plot models based on the extent to which they are either plot-driven or character-driven, as referenced on the left side of the figure by protagonist images taken from Figure 1. Blue denotes plot-driven, while green denotes character-driven.

Event-based models. What we are calling event-based models describe plot as being a progression of particular events, with a focus on the consequences of actions, rather than their motivations. Thus, event-based models only specify the necessary events that should be present in a narrative. Episodic sequencing is considered the primary function of plot, with characters being subservient to the linguistic rules that define the sequencing. For instance, Aristotle maintained that all dramas have a beginning, middle, and end, but he did not characterize what each act must contain, except that one act cannot exist without the presence of the previous one (Aristotle, 335 BCE/1996, p. 13). External interventions or the actions of supernatural forces are far more important than the goals and agency of the protagonist, who is simply the target or recipient of such external forces. In structural narratology (Chatman, 1990; Ricoeur, 1980), plot 
M.Sc. Thesis - C. Tu; McMaster University - Psychology, Neuroscience \& Behaviour

is sometimes viewed as a singular progression or one that is limited in its iterations, since structural narratologists posit the existence of universal elements that are common across all narratives (Georgakopoulou \& De Fina, 2011; Herman \& Vervaeck, 2005). The Russian formalist Vladimir Propp (1928/1958), who strongly influenced the structural narratologists of the $20^{\text {th }}$ century, proposed that all Russian folktales feature the same 31 functions and the same cast of eight dramatis personae. Some sequences of functions are more disjointed than others, most especially the latter functions. For example, the juxtaposition of "punishment" (function 30) and "wedding" (function 31) has a vague causal link except that both events tend to mark the end of a story. Another plot model in this vein is Georges Polti’s (1895) 36 dramatic situations, which outline all of the possible events that can occur in a narrative. In these plot models, it is not important who is carrying out the actions, but only what event sequence is taking place. In structural narratology, plot is mainly about modelling the implicit semiotics that are universal across stories, such as general themes and event types, and it largely ignores the semantic contents of these events, not least the characters of the story (Phelan, 2006). Cohn (2013) presented a grammar for visual narratives which further de-emphasizes the relationship between plot and character. In this view, plot is based on a hierarchical sequencing of episodes in which the "peak" event is at the top of the hierarchy, and where other episodes either lead to or emanate from the peak. Characters are relegated to the realm of semantics and are thus completely separated from the determinants of plot structure. Referring to the analogy in Figure 1A, eventbased plot models highlight the pulley system as the primary force driving character and plot, which is analogous to a plot's abstract syntactic sequencing.

Role-based models. If event-based models describe the progression of a plot with superficial reference to characters, role-based models now include the protagonist as a central 
M.Sc. Thesis - C. Tu; McMaster University - Psychology, Neuroscience \& Behaviour

reference point in the plot, as seen for example in the stereotypical quest plot of a protagonist with a hero's role in the plot. The protagonist is now assigned an arc, but that arc is predetermined by the plot and protagonist's role in it. So, character psychology still plays a minimal role in such models. One of the most popular plot models of this type is Joseph Campbell's (1949) “hero's journey”. Campbell drew from Jungian psychoanalysis and his own theory of myth to create the plot arc or "journey" befitting a hero. This journey outlines the departure of a designated hero from his/her known world toward an unknown world filled with obstacles that shape the hero into a victorious and wiser person before their ultimate return to the familiar world they came from. Similar to Propp's 31 functions, the hero's journey outlines the necessary events that the protagonist must experience in order to fulfill the plot. But these models are still very much plot-driven. The difference is that role-based models such as the hero's journey are focused on the role of the protagonist, while event-based models such as Propp's have little regard for the specifics of characters (Murphy, 2015). Other role-based plot models include Vonnegut's (1981) six story shapes, Friedman's (1955) three plots, Booker's (2004) seven basic plots, Tobias' (1993) twenty master plots, and Weiland's (2016) three types of character transformations. These plot models each describe a list of possible plot types that can account for any story and that outline a designated journey for particular protagonist roles, such as Vonnegut's "rags-to-riches" plot for an impoverished protagonist. Role-based plot models represent the thematic focus of structural narratology (Genette, 1988; Ronen, 1990).

In the 1970's and 80's, there was a push within cognitive psychology to develop “story grammars" of plot structure, and such grammars also fit into what we are calling role-based plot models. Story grammars were developed to account for experimental findings regarding the comprehension and recall of read stories. Such studies demonstrated that well-constructed stories 
M.Sc. Thesis - C. Tu; McMaster University - Psychology, Neuroscience \& Behaviour

have a greater impact on understanding and recall than poorly-structured stories (Bower, 1976;

Graesser, Robertson, Lovelace, \& Swinehart, 1980; Rumelhart, 1975; Trabasso \& Van Den

Broek, 1985). Story grammars outline the basic components that should be present in a story, as well as the proper ordering of these components (Georgakopoulou \& De Fina, 2011; László, 2008; Lehr, 1987; Mandler, 1984), which include an orienting event, a complicating event, and a resolution (Habermas, Meier, \& Mukhtar, 2009; Mandler, 1984; Rumelhart, 1975; Stein \& Glen, 1979). Similar to the hero's journey, the sequencing of episodes in story grammars is highly constrained and invariant, such that changing the order of or omitting any of these events will affect the narrativity and understanding of the story (Mandler \& Johnson, 1977; Mandler, 1984; Thorndyke, 1977). From a psychological standpoint, most story grammars incorporate protagonist reactions, protagonist goal states, and a problem-solving arc in their models, which bring them in the direction of what we are calling psychology-based models. However, one is hard pressed to know that such goal states reside in people, since story grammars present a highly abstract and disembodied view of characters.

Psychology-based models. The third type of plot model in the scheme is the psychologybased model, which is a type of character-driven model. In Figure 1B, the pulley system is gone, and the protagonist instead forges their own path toward their goal, effortfully overcoming obstacles along the way. Story grammars straddle the boundary between role-based and psychology-based models due to their inclusion of emotional reactions and goal states in the model as well as their prototypical problem-solving arc (Black \& Bower, 1980). However, story grammars are weak in their insights regarding character psychology, as they do not explain the character's individuality or the motivations that drive goals and actions to begin with (Phelan, 2006; Theune, Faas, Nijholt, \& Heylen, 2003). In other words, they strongly lack a focus on 
M.Sc. Thesis - C. Tu; McMaster University - Psychology, Neuroscience \& Behaviour character psychology. Cognitive narratologists (e.g., Fludernik, 1996; Herman, 2013; Hogan, 2011; Ryan, 2007), by contrast, have been acutely concerned with character psychology, specifically character consciousness and experientiality. Herman (2004) proposed a theory of process types in which stories are made up of a combination of mental process-types, such as the processes of being, doing, and sensing. Some process-types may define the narrative theme more so than others. Herman called this weighting and ranking of process-types a preference system, where some processes may be preferred over others in particular genres. Thus, unlike plot-driven models, character-driven models such as Herman's are much more open-ended, multidimensional, and psychologically-grounded, allowing for a variety of different plot types due to the combinatorial possibilities of cognitive processes. Palmer $(2004,2010)$ presented an overarching theory of how to treat plot in a character-driven manner. This theory is concerned with how the consciousness of the protagonist is constructed and how it extends into the narration as a thought-action continuum, which contrasts with traditional theories of focalization using a linguistic perspective.

Psychology-driven models such as Herman's and Palmer's offer an important perspective on the narrative analysis of plot, but the potential limitation with these models is that they are more concerned about how readers construct fictional minds and less about how characters themselves mediate narrative progression through embodied experiences. Characters do not just observe the storyworld from within their mind, but they interact with and respond to the storyworld to achieve holistic psychological and bodily experiences. Embodiment is a multifaceted concept that is commonly associated with visceral and kinesic experiences (Bolens, 2012), as well as with mental imagery (Kuzmičová, 2014). However, embodiment also pertains to emotional states of being. Caracciolo (2014) stated in a broad sense that "emotions are bodily 
M.Sc. Thesis - C. Tu; McMaster University - Psychology, Neuroscience \& Behaviour

responses, both because they have an affective component (i.e., they involve bodily feelings) and because Western culture tends to see emotions as closer to our corporeal nature than to conceptual activities or rational thinking” (p. 52). According to Fludernik (1996), there can be "narratives without plot, but there cannot be any narratives without a human (anthropomorphic) experiencer of some sort at some level" (p. 13). Narrative should thus be centered on the “experientiality of an anthropomorphic agent" (p. 26), where she refers to such agents as actants or existents. For Fludernik and other post-classical narratologists, such as Ryan (2007) and Gabriel (2000), characters and their psychology are both the ends and the means of narrative. The agent is the driver of narrative causality, which is very often omitted from the definition of narrative (Ryan, 2007). Narrative is inseparable from human emotion and experience (Bruner, 1986; Hogan, 2010), and so it should follow that plot cannot be separate from human emotion and experience as well. A sequence of events that is devoid of human experientiality should not be considered a narrative, let alone have a plot. Palmer (2010) argued that characters' "beliefs, desires, and other thought processes to a great extent compose the plot" (p. 9, emphasis in original). Hogan (2010:65) described narrative as being "fundamentally shaped and oriented by our emotion systems" and that even "narrative time is fundamentally organized by emotion" (p. 67).

According to Phelan (1987), a character is a synthetic construct with synthetic, mimetic, and thematic dimensions. A character's synthetic dimension refers to their artificial construction as a character, their mimetic dimension refers to the traits that make them appear to be a possible person, and their thematic dimension refers to the ideas that they represent in the narrative. Phelan says that "just as characters are possible persons and carriers of ideas they are also artificial constructs" (p. 284, emphases in original). A plot-driven approach to modelling plot 
M.Sc. Thesis - C. Tu; McMaster University - Psychology, Neuroscience \& Behaviour

structure places the emphasis on the synthetic constructedness of characters, and de-emphasizes the mimetic view that characters are possible people with emotions, intentions, goals, and other cognitive processes. The Embodied Plot model, on the other hand, shifts the focus towards the mimetic view. Instead of merely being plot-constructs, characters themselves construct the dynamics of the plot through their intentions and actions. This is because characters are embodied constructs. They are assumed to be biological beings that have emotions, thoughts, and desires who engage in goal-driven actions to satisfy biological and social needs. In other words, the features of character psychology that are relevant to literature are the features of biological beings possessing bodies and psychologies similar to our own. We use the term embodiment metaphorically. Just as a plot has a metaphorical trajectory (Caracciolo, 2014), the plot is also metaphorically embodied by the protagonist. Plot is usually thought of as an abstract structure without any connection with the body. However, we propose that plot can be viewed as being encompassed within the protagonist's mind and body. While Ryan (1991) and Palmer (2010) have argued that the mental processes of a character compose the structure of a narrative, neither of them have described how these processes are embodied by the character. Emotional appraisals and goal formulation are cognitive processes that metaphorically move the story forward because they drive the protagonist's behavior.

Another idea quite prevalent in narrative theory is that characters are reader-constructs that result from the interpretation of the reader. However, we argue that characters are the vehicles that make this interpretation possible to begin with. As a result, our use of the term embodied is not a direct reference to psychological theorizing about embodied cognition (Goldinger et al., 2016), but instead a use that argues that the reader's interpretation of the story is driven by the psychophysiological processes occurring in the protagonist, as reported in the 
M.Sc. Thesis - C. Tu; McMaster University - Psychology, Neuroscience \& Behaviour

narration. While it is undeniable that the reader cognitively participates in interpreting the narrative and that narrative tension arises in the mind of the reader, the reader's interpretations would not be possible if the protagonist were not seen by the reader as an embodied (biological) being, and the reader would not experience tension unless that tension were empathically anchored to the welfare of the protagonist as a biological being. The reader creates a mental model of the protagonist's mind based on the information presented to them about the protagonist's emotions, goals, and actions (Mar, Oatley, Djikic, Mullin, 2010). The reader may then vicariously experience the emotions of the protagonist (Mar, Oatley, Djikic, Mullin, 2010). The reader's narrative experience is therefore contingent on their empathic engagement with the protagonist's experience of their problem solving arc. We argue that it is the protagonist who mediates the reader's interpretation of the emotional arc by serving as a vehicle for the vicarious experience of emotions by the reader. It is critical to point out that characters are ultimately author constructs, not reader constructs. As Hogan (2013) points out, authors typically begin with prototypes of characters derived from emotion systems, and then flesh out the specific features of the characters in relation to the plot. Numerous practical guides for writers emphasize the prototypical nature of characters (Schmidt, 2001, 2012), and how authors can generate dramatic arcs for them (Weiland, 2016).

The psychology-based models of the cognitive narratologists increasingly argue that the plot-based prioritization of classic theories of plot structure needs to be reversed. Linguistic abstraction and episodic sequencing are not sufficient in explaining a plot's progression, since they overlook the central influence of character. Stories and their characters simulate everyday life (Oatley, 1999), as stories are primarily by, for, and about people trying to make sense of conflicts in the world, be they real or fictional (Herman, 2013; Hogan, 2013). Storytelling is a 
M.Sc. Thesis - C. Tu; McMaster University - Psychology, Neuroscience \& Behaviour

social exercise in depicting, understanding, and manipulating human emotions (Oatley, 1994;

Keen, 2011), and storytelling serves as an adaptive device for social learning and the modeling of social behavior (Bietti, Tilston, \& Bangerter, 2018; Boyd, 2009; Mar \& Oatley, 2008). People are acutely attracted to the experiences of other people, and there might be adaptive advantages to learning about people's problem-solving strategies vicariously through the simulations of real life that occur in stories. It thus follows that narratologists should aim to create plot schemas that model story structure primarily based on characters and their experientiality in the world.

\section{The Embodied Plot model}

While all psychology-based models strongly implicate the protagonist and his/her psychology as being central to the nature of narrative, no model has yet argued that plot structure is embodied by the protagonist and driven by the psychological processes occurring in the protagonist's mind. Hence, our goal in the current section is to make the transition from an abstract character-driven approach to an embodied character-driven approach to both narrative and plot structure through a new model that we call the Embodied Plot model. We thus aim to move beyond character consciousness per se, as per Caracciolo's criticism of Herman and Palmer, and to consider embodiment as a critical factor that underlies a character-driven approach to plot. Embodiment is not being used here in the banal sense of referring to any process that involves a body, but to the idea that the emotional trajectory of a plot's structure is directly related to psychophysiological processes taking place in the protagonist, as related to his/her motivations, goals, and problem-solving strategies. Standard accounts of the dramatic arc are disembodied, and our goal is place this arc where it belongs, metaphorically inside the mind and body of the protagonist. In order to demonstrate the utility of the model, we apply it below to 
M.Sc. Thesis - C. Tu; McMaster University - Psychology, Neuroscience \& Behaviour

a set of well-known fairy tales in the section "An analysis of fairy tales". The selected fairy tales are part of a small corpus of stories examined by Murphy in The Fairytale and Plot Structure (2015), which itself is a critical analysis of Propp's 31 functions.

Figure 3 presents the Embodied Plot (EP) model in graphic form. Before discussing the components of the model in detail, we will present an overview of it. A critical feature of the model is the segregation of a story into two linked realms: the storyworld and protagonist psychology (the lower grey region). The storyworld mainly is comprised of "situations", both static and dynamic. It also contains all of the characters aside from the protagonist, including the primary antagonist. The realm of protagonist psychology is the embodied part of the model, reflecting psychological processes occurring in the mind of the protagonist. Within the model, these processes are organized according to three horizontal tiers that specify the categories of psychological processes that drive the protagonist's actions: 1) emotional appraisals of situations, 2) motivations, goals, and action plans, and 3) decision making. These processes are causally linked to one another through a problem-solving cycle, as triggered by situations in the storyworld that affect the welfare of the protagonist. There are also two vertical columns related to the two key situations in the model: Situation 1 is the trigger that mobilizes the protagonist into action, and is associated with Appraisal 1 and Decision 1, while Situation 2 is the consequence of the protagonist's goal-directed action, and is associated with Appraisal 2 and Decision 2. Importantly, the actions of the protagonist are propelled by two distinct sources: 1) the protagonist's internal psychological motivation to engage in goal-directed actions, and 2) external factors in the storyworld that act as interventions to mobilize the protagonist. Active protagonists generally employ the former, while passive protagonists are often subject to the latter. Finally, the central tenet of the Embodied Plot model is that plot is character-embodied, 
M.Sc. Thesis - C. Tu; McMaster University - Psychology, Neuroscience \& Behaviour

and thus that the dramatic arc of a story maps onto the rises and falls in emotional experience of the protagonist in a story. Hence, the model establishes a strict relationship between plot and character, one in which the protagonist is the driving force for the dynamics of the plot. This is consistent with Palmer's (2010) contention that the psychological processes of the protagonist "compose the plot". As with Palmer, we argue that knowledge about the mind of the protagonist, not least their emotions, is gleaned through the emotional language contained in the narration and dialogue. For the remainder of this section, we will describe in sequence the 14 components that comprise the model, as outlined in Figure 3. Note that processes to the left of the dashed vertical line in Figure 3 are those that precede the triggering event of a story (i.e., component \#3).

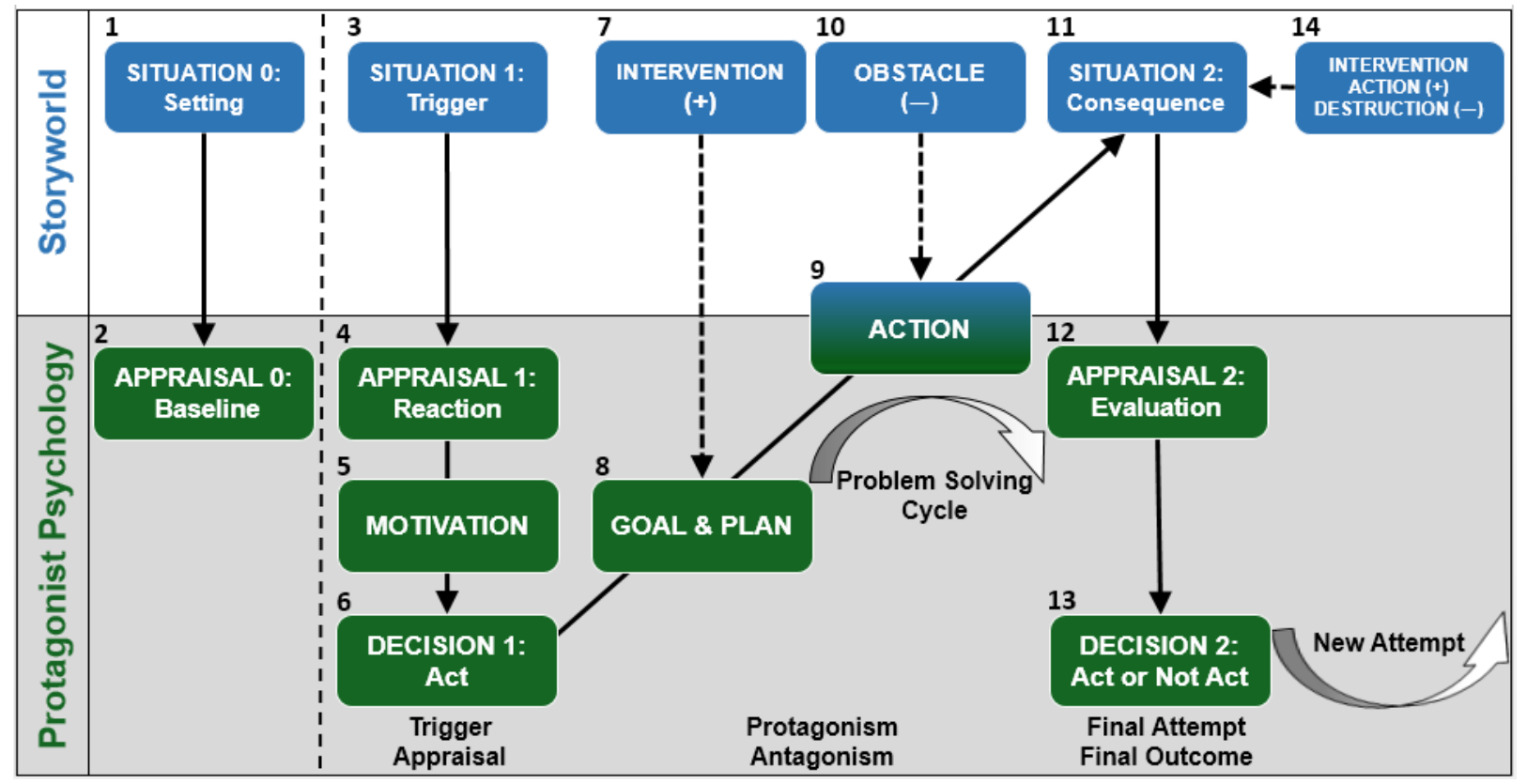

Figure 3. The Embodied Plot model. The model segregates the components of a story into two linked realms: the Storyworld (denoted with blue boxes) and Protagonist Psychology (denoted with green boxes). Processes to the left of the dashed vertical line are those that precede the triggering event. The 14 major components of the model are numbered in sequence. "New Attempt" to the far right of the figure implies that the protagonist's decision to engage in a new goal-directed action brings the cycle back to the Goal \& Plan stage of the model, as shown in Figure 5 below. The plus sign (+) indicates that interventions have a positive influence on the protagonist, while the minus sign (-) indicates that obstacles have a negative influence. At the 
M.Sc. Thesis - C. Tu; McMaster University - Psychology, Neuroscience \& Behaviour

bottom of the figure are listed plot constituents that are described in Figure 4 and the section "The Constituents of Plot Structure".

1. Situation 0: Setting. Situations can be static or dynamic. The main static situation of a story is the setting, which establishes ongoing, unchanging features of the story. Other situations are dynamic, such as the obstacles and interventions that have a behavioral influence on the protagonist. There are at least three aspects to the setting of a story: time, place, and social setting. The social setting refers to the norms of behavior in the storyworld, spanning from very permissive to very restrictive societies. One important aspect of the social setting is the protagonist's social status within the storyworld (e.g., low to high).

2. Appraisal 0: Baseline. Perhaps the most important psychological component of the EP model consists of emotional appraisals, as described in appraisal models of emotion in cognitive psychology (Ortony, Clore \& Collins, 1988). Appraisals are characterized by both the valence and intensity of the emotion. Valence is typically a discrete variable, being either positive (e.g., happy) or negative (e.g., sad), whereas intensity is a continuous variable, spanning from low intensity (e.g., glad) to high intensity (e.g., ecstatic). Situations that are appraised as positive are generally supportive of an individual's survival, whereas situations that are appraised as negative are often threats to survival. Appraisal 0 is the emotional appraisal of the setting of the story, and establishes the baseline emotional tone for the protagonist, in other words the equilibrium point of the story (Todorov \& Weinstein, 1969). In many stories, the protagonist starts out in an emotionally neutral situation. However, in stories of oppression, such as Cinderella, Appraisal 0 establishes a baseline of chronic negativity for the protagonist. While the model in its current form does not deal with the protagonist's personality traits, it is likely that the appraisal components of the model are highly influenced by such personality traits (Heppner \& Krauskopf, 1987). 
M.Sc. Thesis - C. Tu; McMaster University - Psychology, Neuroscience \& Behaviour

3. Situation 1: Trigger. Having established an emotional baseline for the protagonist through Appraisal 0, the story's actual events begin with Situation 1, which is the initiating event or trigger for the story. The triggering event is a situation in which a person or force disrupts the protagonist's baseline condition or equilibrium state. This component is present in many plot models, including the hero's journey and story grammars, where it is referred to variously as the initiating, complicating or inciting event. The trigger can be an external force (e.g., a person) or an internal force (e.g., the self), but it is very often an antagonistic person or force. To the extent that the trigger represents the actions of the primary antagonist of the story, we can imagine a classification of antagonists into four basic types: oppressors, aggressors, deceivers, and rivals. The oppressor is someone who infringes on the protagonist's independence and agency by being emotionally abusive and by having prohibitive authority over the protagonist, such as Cinderella's stepmother. The aggressor is someone who is physically threatening to the protagonist. Such a person often appears later in the story as an obstacle, rather than as a trigger. The deceiver is an aggressive antagonist whose motivations and actions the protagonist is unaware of. Deceivers are usually enticing, charismatic, and persuasive characters, as opposed to oppressors and aggressors, who are coercive. The rival is an antagonist of matched status and agency to the protagonist, since the protagonist sees such a person as a competitor. The protagonist of a story will have different emotional reactions to different triggers based on the properties of these different types of antagonists.

4. Appraisal 1: Reaction. Appraisal 1 is the protagonist's emotional and evaluative reaction to the triggering event in Situation 1. According to appraisal theories of emotion, events themselves do not carry an intrinsic emotional meaning for people, but are instead appraised based on an assessment of the situation's impact on the livelihood of a person, again where 
M.Sc. Thesis - C. Tu; McMaster University - Psychology, Neuroscience \& Behaviour

positive appraisals occur for things that are supportive of survival, and where negative appraisals occur for threats (Heppner \& Krauskopf, 1987; Lazarus, 1968; Roseman, 1991). Hence, an event cannot be classified as a trigger until the protagonist assesses it as a problem that needs to be addressed (Hogan, 2011). For instance, Jack in Jack and the Beanstalk has a cow that no longer provides milk (trigger). However, Jack does not have a negative appraisal of the trigger, but instead tells his mother to "cheer up" since he believes they can easily overcome the situation by either finding a job or selling the cow. Emotional appraisals of storyworld situations are the core of protagonist embodiment since the protagonist is assessing the impact of the triggering situation on their livelihood. Appraisal 1 is the protagonist's initial emotional change, or shift, from the emotional baseline introduced as Appraisal 0, and this appraisal generally initiates a problem-solving cycle that defines the trajectory of the plot. The protagonist's problem-solving strategy can involve either approach or avoidance.

Since Appraisal 1 can be either a positive or negative assessment of the triggering situation, this establishes two basic types of central conflicts for stories based on prospective emotions of either hope or apprehension, respectively. This corresponds with the Proppian notion that the complication of a story can be based on either a desire or a lacking (Murphy, 2015). An emotional appraisal that involves feelings of ambition and desire, or a rise in emotional state, constitutes what we will call a striving conflict. Protagonists experiencing striving conflicts often wish to gain something of value that they desire, as seen with the protagonists of adventure or quest stories. They are thus typically optimistic and hopeful about the challenge. On the other hand, a protagonist can have an emotional appraisal that involves feelings of anxiety and thus a fall in emotional state. This will constitute what we will call a coping conflict. Protagonists that experience coping conflicts are often faced with chronic oppression from an antagonist, and they 
M.Sc. Thesis - C. Tu; McMaster University - Psychology, Neuroscience \& Behaviour

may therefore be pessimistic and apprehensive about their situation. Different protagonist attitudes towards the triggering situation will create different behaviors and therefore different action/event sequences. In appraising a situation, the protagonist establishes a state of dissatisfaction with their current situation and generates a prospective emotion based on either ambition and hope (striving story) or fear and apprehension (coping story). Hence, a critical aspect of Appraisal 1 is that it stimulates the protagonist's motivation to make a change for the better, either to achieve a desirable improvement (striving story) or to relieve a negative situation and thereby return to a neutral baseline (a coping story).

5. Motivation. The protagonist's emotional reaction to the trigger stimulates the motivation to act, which provides a forward direction to the narrative. If it did not, there would be no story. In terms of the causal structure of the EP model, motivation establishes a psychological relationship between the protagonist's emotional appraisal and their decision to take action (Heckhausen \& Gollwitzer, 1987). While Appraisal 1 is a retrospective evaluation of a situation, motivation is a prospective reflection on a desired future situation (Austin \& Vancouver, 1996; Nuttin, 2014). Motivation can be driven by an optimal level of optimism (striving conflict) or pessimism (coping conflict), as these two perspectives refer to different attitudes towards the future (Lopes \& Cunha, 2008). Motivation is a critical prerequisite for engaging in the problem solving cycle (French \& Thomas, 1958; Mayer, 1998). It thus represents the beginning of a rise in valence and intensity in the emotional state for the protagonist.

Motivation interfaces with two other important concepts in the psychology of action: intentionality and agency. Intentionality reflects the fact that protagonists are active agents that are able to engage in actions to achieve their goals. This is opposite to a view of people as being subject to external forces that determine their destiny, as was discussed above in our analysis of 
M.Sc. Thesis - C. Tu; McMaster University - Psychology, Neuroscience \& Behaviour

plot-driven narrative models. The notion of protagonist intentionality been central to many theories in cognitive narratology (Bruner, 1986; Herman, 2004, 2013; Hogan, 2011). Similar to intentionality, agency refers to the sense of having voluntary control over one's actions and one's ability to achieve desired outcomes (Haggard, 2017). Hence, the motivation to act is intimately connected with the belief that one has the ability to produce such an action. In literature, as in real life, there are high-agency and low-agency individuals. Whereas the classic heroes of literature are high-agency individuals, low-agency protagonists provide problems for the progression of a story, since stories are based on the changing states of a protagonist. In order for the stories of low-agency protagonists to not end prematurely, external interventions are generally necessary to propel the story, as will be described in component \#7 below.

6. Decision 1: Act. A person could have the motivation to bring about a positive life change, but unless the person makes a decision to act, then the desire is functionless. Decision making is defined as "committing oneself to a course of action" (Lipshitz, Klein, Orasanu, \& Salas, 2001), typically the action associated with the greatest reward potential (Simon, 1959). This commitment to a course of action generally occurs in the face of multiple alternatives (Simon, 1959). Naturalistic or everyday decision making is the type that occurs in real-world situations. Unlike formal or instrumental decision making, everyday decision making does not typically make use of optimizing strategies (Kahneman, Slovic, \& Tversky, 1982; Klein, 2008), since it is often biased by emotions (Kemdal \& Montgomery, 2002; Mosier \& Fischer, 2010; Tversky \& Kahneman, 1991) and self-concepts (Verplanken \& Holland, 2002). A low-agency protagonist may choose to not act when confronted with a problem, especially if they feel fear or pain. Decision making sits at a critical intermediate point between motivation (i.e., desires, intentions) and action planning because it determines the active initiation of the problem-solving 
M.Sc. Thesis - C. Tu; McMaster University - Psychology, Neuroscience \& Behaviour

cycle, thereby comprising a critical part of the narrative progression and is an indicator of protagonist agency. A protagonist who is willing to pursue a change in their situation is motivated to resolve their problem and is considered proactive, determined, and assertive. As was mentioned above for motivation, a decision by the protagonist not to act on their desires would result in the premature termination of a story. Hence, the typical decision that is made by the protagonist at this point in most stories is the decision to act, where this commitment signals a maintenance of the emotional rise that was initiated by the protagonist's motivation. The decision to act is dependent on the incentives of the situation, since people make assessments of the rewards and risks of taking action (Phelps, 2008). The protagonist will be more inclined to act if they feel confident about their course of action and are aware of the potential rewards and risks of attempting an action (Lebreton, Abitbol, Daunizeau, \& Pessiglione, 2015; Portelli, 2013; Weber \& Johnson, 2009). The exceptions are stories of passive protagonists who choose not to act. The only way to avoid a premature termination of the story is to introduce an external intervention that overcomes the protagonist's resistance to act.

The decision to act is the initiating event that triggers the problem-solving cycle of the narrative. We argue, as have others before us (Rumelhart, 1980), that plot structure is underlain by a basic process of personal problem solving, often times involving social conflicts. The problem solving cycle is shown in Figure 3 as a series of causally-linked processes that extend from Decision 1 all the way to Decision 2, with the potential for new attempts after Decision 2. Heppner and Krauskopf (1987) and Marsiske and Margrett (2006) defined real-life personal problem solving as a goal-directed sequence of affective, cognitive, and behavioral processes that an individual employs to resolve a challenge or mismatch between their current state and their desired state. In like form, the process of everyday personal problem solving has a narrative 
M.Sc. Thesis - C. Tu; McMaster University - Psychology, Neuroscience \& Behaviour

flavor to it, in which a person attempts to overcome obstacles in order to achieve a goal. As alluded to in Appraisal 1, the problem solving cycle is highly contingent on emotional appraisals, since appraisals determine if an individual perceives a situation as being a problem to begin with. Problem solving is a highly embodied process as it involves the body directly interacting with the physical world, such as during appraisals, decision making, and goal-directed actions, but also indirectly interacting with the world by reasoning about the world and using mental models to imagine possible solutions to problems (Wilson, 2002). Problem solving is an emergent stepby-step process that is directed by the individual as they update their strategy by evaluating their past behavior, current situation, and future consequences (Palmer, 2004:120; Teun van Dijk, 1976). It is not externally determined by the plot and storyworld. Traditional plot-driven plot models do not consider these emergent and dynamic properties of problem solving that are driven by the protagonist. Instead, plot-driven models view problem solving as a path that the protagonist follows, rather than as one that the person creates (see Figure 1).

7. Intervention. The EP model underlines the fact that the actions of the protagonist are propelled by two distinct sources, and these are situated in distinct realms in the model: 1) the protagonist's intrinsic psychological motivation to act, and 2) extrinsic factors in the storyworld that function as interventions. Active protagonists generally employ the former, while passive protagonists are often subject to the latter. Hence, instead of a protagonist-mediated action, an intervention might occur at this stage in the story in order to reverse the decision of the protagonist from inaction to action, as in the case of the influence of the fairy godmother in reversing Cinderella's decision to not go to the ball. An intervention is therefore the action of an enabler who steps in to guide, assist, or substitute for the protagonist in improving their situation. The nature of the intervention is another indicator of the protagonist's agency. When an 
M.Sc. Thesis - C. Tu; McMaster University - Psychology, Neuroscience \& Behaviour

intervention is sought by the protagonist, this usually means that the protagonist is proactive in seeking help. Optimistic individuals tend to be more proactive than pessimistic individuals in seeking help and social support (Scheier, Carver, \& Bridges, 1994). However, when an intervention appears spontaneously in a story, this often reflects a passive protagonist who is waiting for help to arrive or who is resistant to acting. Whether solicited or unsolicited, weak interventions have limited influence over facilitating the protagonist's actions, whereas strong interventions may outright replace the protagonist's internal driving force by transporting the protagonist to their desired outcome without them having to act on their own. Interventions are common elements in stories, since problem solving is usually a collaborative and social process (Lee, 1997; Nelson-Le Gall, 1981), as real people and protagonists alike seek help and guidance when deciding on a course of action.

8. Goal and Plan. Goals and plans are causally linked to one another, as well as to the decision-making and appraisal processes that elicit them. Goal formulation is the proposal of a specific solution to an identified problem (Heppner \& Krauskopf, 1987). While the phases of Appraisal 1, Motivation, and Decision 1 stimulate the protagonist to initiate the problem-solving cycle, the process of goal formulation directs and organizes behavior, thereby making problem solving a goal-directed process (Heppner \& Krauskopf, 1987). Action planning follows closely with goal formulation because, in thinking about a goal, an individual will also think about the experiences and resources that they can draw from that will help bring their goal to fruition (Heppner \& Krauskopf, 1987). We will only consider situations in which the goal and action plan are congruent, as is the case in the majority of stories. We thus combine the processes of goal formulation and action planning as component $\# 8$ in the model. As was mentioned in the Introduction, goal states are a central component of all of the classic story grammars of the 
M.Sc. Thesis - C. Tu; McMaster University - Psychology, Neuroscience \& Behaviour

1970's and 80's. The role of goals in guiding motivated action during problem solving is wellestablished in the psychology literature (Schank \& Abelson, 1977). The protagonist's goal is often congruent with their emotional appraisal. If the protagonist has an emotional appraisal defined by feelings of ambition and desire, then the protagonist will usually have a materialistic goal in which they hope to gain a positive reward, such as an improvement in status, wealth, or power. If the protagonist has an emotional appraisal defined by feelings of anxiety, then it usually follows that the protagonist will derive an emotion-oriented goal in which they want to relieve such negative emotions.

While a goal represents the desired outcome, a plan represents the specific means by which the goal can be achieved through a series of actions. There are many different types of plans that can emanate from a single goal, and plans are in almost all cases concordant with goals. Plans differ in features such as awareness, risk, effort, cost, and unintended consequences. Thus, the protagonists in two different stories may have similar goals, but be distinguished by the plan and action by which they seek to achieve their goals. Hence, action planning, similar to the decision to act, is an important determinant of protagonist agency, as the protagonist must appraise their own ability to achieve their goal (Butler \& Meichenbaum, 1981; Heppner, Witty, \& Dixon, 2004). As mentioned previously, a proactive protagonist may either act alone or formulate a plan that includes the soliciting of an intervention by enablers to help move their plan along.

9. Action. Actions are the behavioral outcome of goal formulation and action planning, and are therefore the culminating response of a problem-solving cycle (Heppner \& Krauskopf, 1987). Having a goal and a plan will not be sufficient in successful problem solving if the protagonist does not have the agency or skill to carry out the plan (Mayer, 1998). As such, 
M.Sc. Thesis - C. Tu; McMaster University - Psychology, Neuroscience \& Behaviour

actions reveal a further level of agency of the protagonist, since actions reflect the protagonist's direct ability to initiate and effect change (Gallagher, 2000). Together with goal formulation and action planning, actions represent an implicit sustained rise in the emotional state in the psychology of the protagonist, one that was stimulated during the motivation phase of the model, since the protagonist is making forward progress towards realizing their goal. It is important to note that the protagonist-mediated action is the only component of the EP model that is present in both realms of the model: it is an embodied protagonist process, and yet it occurs physically in the storyworld, which is why it is double-colored in Figure 3. By considering the interplay between events in the protagonist's psychological realm and those in the storyworld, the protagonist is recognized as a high-level agent (Vallacher \& Wegner, 1989) who effects change in the story, rather than someone who merely experiences effects imposed on them from the storyworld.

10. Obstacle. The protagonist's goal-directed actions can be disrupted by obstacles. Obstacles are usually external forces situated in the storyworld produced by antagonistic individuals or forces (Murphy, 2015). While interventions tend to occur at decision points in order to enable the protagonist's actions, obstacles tend to occur during an action in order to disrupt the protagonist and thus alter the intended outcome of their goal-directed action.

11. Situation 2: Consequence. The protagonist's goal-directed action leads to a new situation in the storyworld, namely the outcome of the action and its consequences for the protagonist's welfare. A successful outcome indicates that the protagonist was able to achieve the intended goal. A failed outcome indicates that the protagonist was unsuccessful. Failure could be due to either protagonist-related factors (e.g., low motivation, poor planning, 
M.Sc. Thesis - C. Tu; McMaster University - Psychology, Neuroscience \& Behaviour

insufficient agency) or to the effects of obstacles that thwart what might have been an otherwise successful attempt.

12. Appraisal 2: Evaluation. Appraisal 2 is the protagonist's retrospective emotional appraisal of the outcome of their goal-driven action. Research on emotion indicates that action evaluation is an affective response in which the individual compares the favorability of the outcome to their goal (Carver \& Scheier, 2001; Heckhausen \& Gollwitzer, 1987; Ortony, Clore \& Collins, 1988). If the outcome of the action is concordant with the goal, then an emotion of positive valence will be registered (e.g., satisfaction, happiness). However, if the outcome is incompatible with the goal, then an emotion of negative valence will be registered (e.g., dissatisfaction, frustration). It is important to note that a protagonist can have a positive appraisal of an incongruent outcome if that outcome yielded an unexpected consequence that is pleasing to the protagonist. From a narrative standpoint, a positive appraisal can lead to the end of a story, since the problematic situation appears to have been resolved. Hence, the protagonist will make the decision not to act any further. However, a negative appraisal of the outcome can lead the protagonist to decide on making a new attempt at solving their problem by re-activating the entire problem-solving cycle and developing a new plan of action. In the analysis of fairy tales later in the paper, these new attempts will be represented graphically by reduplicating the EP model from the Goal/Plan stage onward (see Figure 5 for the analysis of Jack and the Beanstalk). Episodes in which an obstacle disrupts a protagonist's goal-directed action can cause the protagonist's level of distress to increase. This fall in emotional state can motivate the protagonist to intensify their efforts to attaining their goal (Carver \& Scheier, 1990; Locke, 1996; Segerstrom, Tsao, Alden, \& Craske, 2000), or it can debilitate the protagonist's motivation if the goal appears too difficult to attain or the obstacle seems too large and persistent (Förster, Grant, 
M.Sc. Thesis - C. Tu; McMaster University - Psychology, Neuroscience \& Behaviour

Idson, \& Higgins, 2001; Higgins, Shah, \& Friedman, 1997). Each of the protagonist's problemsolving cycles therefore begins and ends with an emotional appraisal of their current situation that leads to a decision point of whether to proceed or to terminate the series of goal-directed attempts.

13. Decision 2: Act or Not Act. As just mentioned, a negative Appraisal 2 can serve as a trigger to engage in a second protagonist-mediated action and thus a new attempt at solving either the same or a new problem. Decision 2 thus reflects the protagonist's resiliency and their willingness to modify their goals and courses of action (Heppner, Witty, \& Dixon, 2004). It reflects the level of protagonist agency as well. A persistence towards goal attainment after repeated failures is also known as escalation behavior, where the individual must decide on whether to continue with or withdraw from their course of action (Fox \& Hoffman, 2002). From a narrative standpoint, a decision to act at Decision 2 will add additional episodes to the story, compared to a story that ends after a single attempt. Heppner and Krauskopf (1987) described problem solving as a "highly interactive, and intermittent process" that may require many decisions and goal modifications in order to reach the final resolution. Kemdal and Montgomery (2002) argued that decision making can include "cycles of actions and reactions." In addition, their theory contends that problem solving requires continuous interactions with and feedback from the environment, wherein the individual assesses the outcome of their actions and updates their next actions accordingly. Having multiple problem-solving attempts will lead to the expansion of a story, making it more complex. The EP model shares with story grammars the ability to incorporate multiple problem-solving episodes in a single story (Mandler, 1982; Rumelhart, 1980). This process of iterative bouts of problem solving demonstrates a strong similarity with models of creativity, in which the creator undergoes multiple rounds of trial and 
M.Sc. Thesis - C. Tu; McMaster University - Psychology, Neuroscience \& Behaviour

error in order to generate a creative product that conforms with the germinal idea that drove the work (Mace \& Ward, 2002). Stories are ultimately endpoint-driven (Abbott, 2008), where the valence of the final outcome becomes a major factor in binarily classifying stories into happyending and sad-ending varieties. The EP model is able to differentiate between different types of positive and negative endings in a way that traditional story grammars cannot. Not all happy endings are created equally, as there are different emotional trajectories that the protagonist can experience in order to arrive at the same ending.

14. Intervention Action or Destruction. Finally, the EP model includes a number of storyworld factors that can either positively or negatively propel a story toward its ending without a protagonist-mediated action. Sometimes the protagonist might not have the intention or motivation to begin a new problem-solving cycle, and so an intervening force may usher the protagonist into a new episode. At other times, the protagonist's story may be temporarily suspended, and the story may shift focus to another character, as in the case of the prince's quest to find Cinderella, which is completely external to Cinderella's own goal-directed actions. Apart from an intervention action, there may also be a destructive force that eliminates the protagonist altogether, thereby bringing the story to an end, such as the case in tragedies where the protagonist is killed or dies otherwise.

The constituents of plot structure. Another way of visualizing the Embodied Plot model is to frame it in the manner employed in the study of story grammars, which organizes plots hierarchically according to a series of "constituents" (Cohn, 2013). However, in contrast to previous plot models, we include character processes as fundamental constituents. As shown in Figure 4, the model is organized according to three phases, each of which is comprised of two paired constituents. Together, these phases comprise a sequence of personal problem solving 
M.Sc. Thesis - C. Tu; McMaster University - Psychology, Neuroscience \& Behaviour

(Heppner \& Krauskopf, 1987). (The constituents are shown at the bottom of Figure 3 in order to create a linkage to Figure 4.) The beginning of a story is made up of "problem establishment", comprised of the triggering situation and the protagonist's psychological reaction to it as an emotional appraisal. The second phase, called "protagonist's attempt", involves one or more attempts by the protagonist to realize his/her goal of overcoming the problem. The first constituent of this phase, called protagonism (Brown et al., 2019), refers to the protagonist's goal-directed actions as being the drivers of the story, underlain by the critical psychological processes of motivation, agency, decision making, goal formulation, action planning, and action execution that make up much of the Embodied Plot model. In the vast majority of cases, the protagonist's action will be opposed in some manner, creating obstacles to goal achievement. This makes up the complementary constituent of "antagonism", most commonly manifested by an antagonistic character (a "villain"). The last phase, called "problem outcome", results in a concluding situation for the protagonist. Because a story might have multiple protagonist attempts, the "problem outcome" phase of a story only represents the final attempt and final outcome. 


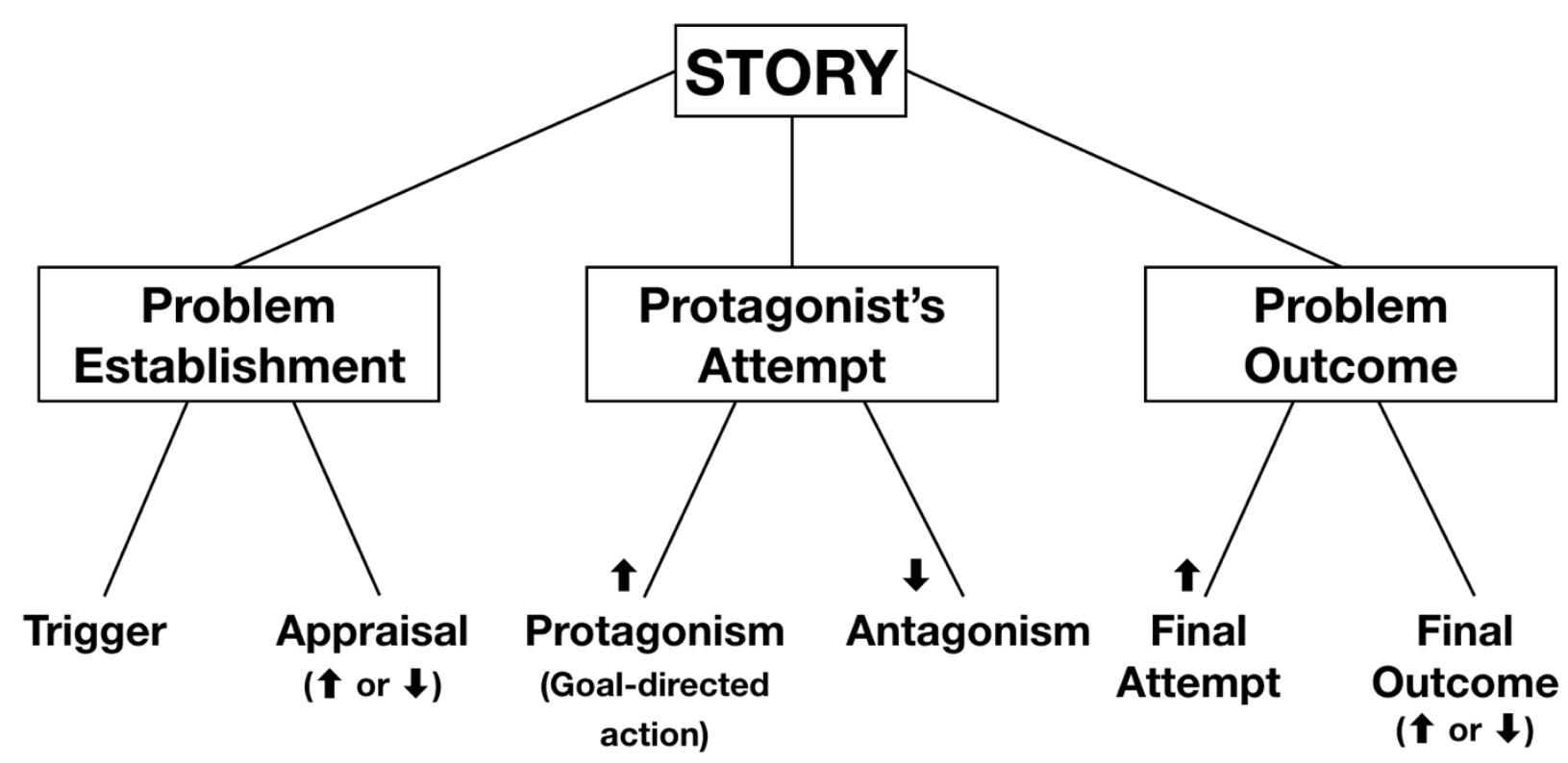

Figure 4. The basic constituents of a plot according to the Embodied Plot model. The schema represents the problem-solving cycle of the central protagonist. The term "protagonism" refers to the protagonist's goal-directed actions, which propel the plot. The upward and downward arrows represent, respectively, emotional rises and falls for the protagonist, as was described for the individual components of the EP model.

\section{An analysis of fairy tales}

Having presented a detailed description of the EP model and its constituent structure, we will now apply the model to a number of well-known fairy tales in order to show how the dramatic arc of each story can be mapped onto the psychological states of the protagonist by means of emotional rises and falls. We will focus on a small number of familiar fairy tales that were analyzed according to a Proppian perspective by Murphy (2015). In particular, we will analyze 1) a striving story with an active protagonist (Jack and the Beanstalk), 2) a coping story with a reactive protagonist (Cinderella), and 3) a story lacking protagonist-driven actions in order to show the effects of interventions on the protagonist (Tom Tit Tot). In Figures 5-7, the black arrows indicate protagonist-driven actions, whereas the red arrows indicate external effects produced by interventions and obstacles. 
M.Sc. Thesis - C. Tu; McMaster University - Psychology, Neuroscience \& Behaviour

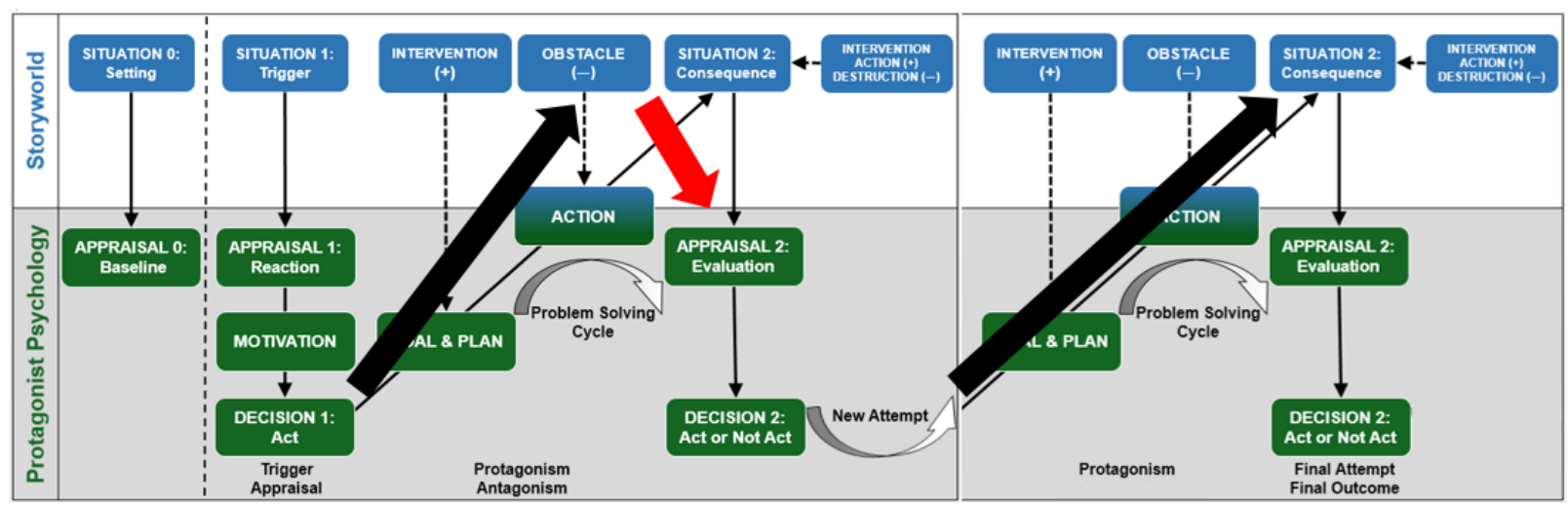

Figure 5. Jack and the Beanstalk (Jacobs, 1890). Jack has a desirous Appraisal 1, resulting in a striving conflict (emotional rise). He encounters the ogre, who serves as an obstacle (fall). He overcomes the ogre by killing him (rise). The plot follows a rise-fall-rise emotional trajectory. Black arrows refer to goal-driven actions by the protagonist, while red arrows refer to external effects acting on the protagonist. Note that the protagonist's second goal-direction action is shown by a reduplication of that part of the EP model.

Jack and the Beanstalk. Jack's story can also be condensed into two key goal-directed cycles: 1) he desires adventure and wants to improve his financial situation, so he trades the cow for the beans and then climbs up the beanstalk, but he is thwarted by the ogre, and 2) Jack wants to stay alive, and so he kills the ogre. Figure 5 depicts this condensed interpretation of the plot of Jack and the Beanstalk. Jack has a low emotional baseline since he and his mother are poor. The cow has suddenly stopped giving milk (trigger). In response to this situation, Jack appraises the trigger positively by viewing it as an opportunity to gain something of value. Jack's appraisal of the trigger is therefore driven by feelings of ambition and desire, which means that he has a striving conflict, marking the beginning of an emotional rise. He is highly motivated to act so as to improve his financial situation. He is confident in his goal and plan, even believing that accepting the magical beans in exchange of the cow was a far trade, despite his mother scolding him about the transaction. So far, Jack's story has been a continual emotional rise, as shown by the single black arrow in Figure 5 that spans from Decision 1 across the causally-linked Goal, Plan, and Action processes. All goal-directed actions are implicit emotional rises in the EP 
M.Sc. Thesis - C. Tu; McMaster University - Psychology, Neuroscience \& Behaviour

model, as the protagonist is making forward progress towards achieving their goal. Jack, while still working towards the same goal of financial improvement, climbs the beanstalk that has grown overnight, and he manages to steal several valuable items from the ogre's home (i.e., successful attempts). We have collapsed Jack's repeated successful attempts into one cycle. On his third trip, the ogre discovers Jack stealing his golden harp (obstacle interrupts action shown by the falling red arrow), and Jack runs down the beanstalk, calling on his mother to give him an ax (decision to act, new cycle, rising black arrow). Jack uses the ax to cut the beanstalk in half, leading to the death of the ogre, and permitting Jack and his mother to be able to live happily with the things that he stole (successful attempt).

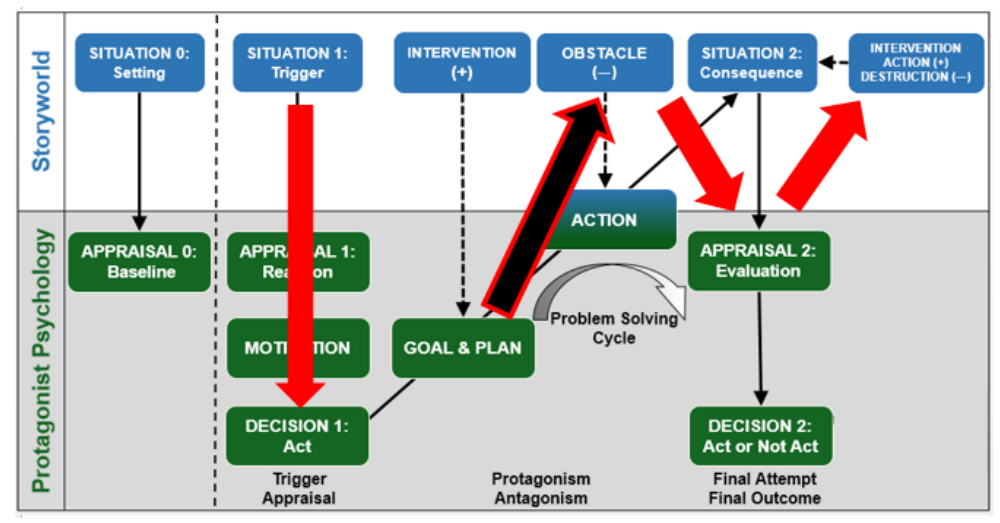

Figure 6. Cinderella (Perrault, 1697/1889). Cinderella has an anxious Appraisal 1, resulting in a coping conflict (emotional fall). Cinderella's fairy godmother helps her prepare for the ball on the condition that Cinderella performs a set of tasks (intervention-mediated rise, black arrow with red outline). The clock striking midnight while Cinderella is at the ball is an obstacle that pressures her to return home (fall). Cinderella's identity is discovered by the prince, leading to a proposal of marriage (intervention action, rise). The plot follows a fall-rise-fall-rise emotional trajectory. Red arrows refer to external effects acting on the protagonist, and the black arrow with the red outline refers to a protagonist action enabled by an intervention.

Cinderella. The character of Cinderella, compared to that of Jack, is a passive protagonist. Cinderella has a negative emotional baseline, as she is abused by her stepmother and stepsisters for most of her life. Cinderella is not allowed to attend the upcoming ball (trigger) and 
M.Sc. Thesis - C. Tu; McMaster University - Psychology, Neuroscience \& Behaviour

cries (Appraisal 1). Cinderella therefore experiences a coping conflict, as her appraisal of the trigger is defined by feelings of anxiety. She is dejected and so does not have the motivation to act. This fall in emotionality is depicted by the first red arrow in Figure 6 that spans from the Trigger across Appraisal 1 and Motivation towards Decision 1. The arrow is red because Cinderella's agency is oppressed by her stepmother, who is an external storyworld influence. Next, Cinderella's fairy godmother arrives and informs her that she can help her go to ball but that she requires Cinderella to retrieve items in the garden (intervention). Cinderella is able to attend the ball (successful action). Figure 6 depicts this progression as a goal-directed action mediated by an intervention in which the fairy godmother enables Cinderella to realize her goal, but does not completely substitute Cinderella in acting to achieve it, as Cinderella must also exert effort on her own part. Hence, the rising goal-directed arrow in Figure 6 is black but is outlined in red to indicate a protagonist action enabled by an intervention. Cinderella meets the prince, which is an unexpected outcome, but the clock strikes midnight (obstacle, falling red arrow), and Cinderella must return home. After this, the story's focus shifts towards the prince's quest to find Cinderella (intervention action). Cinderella is no longer active until the Prince arrives, when she tries on the slipper, leading to a proposal of marriage from the prince. In Figure 6, this intervention-led episode is depicted by the final rising red arrow that is situated in the storyworld. 
M.Sc. Thesis - C. Tu; McMaster University - Psychology, Neuroscience \& Behaviour

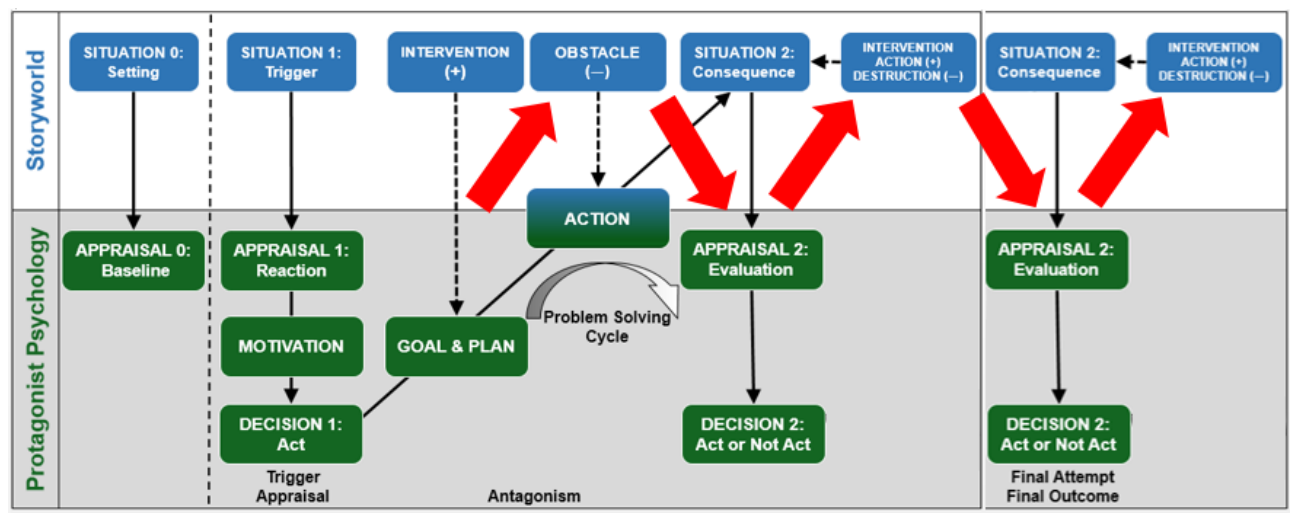

Figure 7. Tom Tit Tot (Jacobs, 1890). The protagonist, who is unnamed, is married off to the king by her mother (emotional rise). She is forced to spin skeins in exchange for her life, but she lacks the knowledge to do this (fall). Tom Tit Tot arrives to accomplish the task for her on the condition that she guess his name after a month (rise). She becomes worried when she cannot guess his name by the end of the month (fall). She hears the king mention his name and is able to correctly guess it (rise). The plot has a rise-fall-rise-fall-rise emotional trajectory. Red arrows refer to external effects acting on the protagonist. Note that the plot of this story completely lacks goal-driven actions by the protagonist.

Tom Tit Tot. This is an example of a story that lacks protagonist-mediated actions. The protagonist's progression is mediated by interventions alone, hence highlighting the duality between goal-directed actions and interventions in plots. The story begins with the protagonist at a neutral baseline eating her mother's pies. The mother complains about her daughter eating the pies, and a king passing through the street mishears the mother as saying that her daughter can spin skeins. The king makes an offer to marry her daughter, and the mother agrees (intervention action, rising red arrow in Figure 7). So far, the story is driven by the mother and the king. The protagonist is enjoying the newfound life that has been arranged for her by her mother. However, she encounters her first conflict when she learns that she must spin skeins in exchange for her life (anxious appraisal of the obstacle, falling red arrow). The protagonist is dejected and does not act until the arrival of an intervention. Tom Tit Tot offers to spin the skeins for her on the condition that she guess his name within a month. She agrees. This intervention action is depicted by the third rising red arrow in Figure 7. The protagonist is unable to guess Tom Tit 
M.Sc. Thesis - C. Tu; McMaster University - Psychology, Neuroscience \& Behaviour

Tot's name and becomes worried (obstacle, falling red arrow). She overhears the king talking about a little creature by the name of Tom Tit Tot (intervention, rising red arrow), which allows her to correctly guess his name and be free of him (intervention-mediated success).

These few examples of fairy tale plots demonstrate the utility of the distinction between protagonist-driven actions and external factors that act on the protagonist, whether supportive (interventions) or obstructive (obstacles). They also demonstrate the contrast between strivingtype stories and coping-type stories, as based on the emotional valence of the protagonist's appraisal of the triggering situation. Since this distinction is based on an analysis of the initial situation, it is thus completely independent of the happy-ending vs. sad-ending distinction regarding the valence of the final outcome. These examples demonstrate that the analysis of the dramatic arc of the story is tightly connected with the psychological processes occurring in the mind of the protagonist throughout the story, including prospective emotions related to future actions and retrospective emotions about the outcomes of past actions.

\section{Discussion and limitations}

In the current paper, we have offered an embodied model of plot structure that is not only character-driven but character-embodied. We argue that plot structure is isomorphic with the psychological experience of the protagonist inside the storyworld, and that the dramatic arc of plots is attributable to psychological processes and problem-solving dynamics occurring in the mind of the protagonist. The notion of an arc is abstract and ambiguous unless it is explained with reference to psychophysiological processes taking place in the protagonist, as related to authorial and reader-based conceptions of the protagonist's motivations, goals, and problemsolving strategies. Conceptualizing the arc of a plot as a rise and fall in "tension" without 
M.Sc. Thesis - C. Tu; McMaster University - Psychology, Neuroscience \& Behaviour

attributing that tension to characters and their emotions only begs the question of what the tension should be attributed to. This suggests that the historical emphasis in literary theory on episodic structure per se may be overstated, and that a more protagonist-driven approach to narrative should focus on character processes, most especially the psychological dynamics of the central protagonist.

Innovations of the EP model compared to previous plot models include: 1) segregation of the story's components into protagonist psychology and the storyworld; 2) a rich psychology for the protagonist that includes emotional appraisal, motivation, intentionality, agency, decision making, goal formulation, and action planning, as organized into a psychological problemsolving sequence; 3 ) formulation of the dramatic arc of the plot in terms of the emotionality shifts experienced by the protagonist, as associated with psychological responses to both external and internal factors; 4) the proposal that stories can be classified not just by the valence of the ending (happy vs. sad ending), but by the valence of the protagonist's emotional appraisal of the triggering situation into striving and coping stories; 5) a differentiation of two external factors acting on the protagonist along the lines of valence into interventions (positive influence) and obstacles (negative negative); and 6) the proposal that the protagonist's actions in a story can be positively propelled by two distinct sources: internal sources based on the protagonist's motivation and goals, and by external sources coming from interventions.

The aim of the fairy tale analysis was to demonstrate that the EP model is able to differentiate the dramatic arcs of contrastive stories. We contend that the protagonist drives the dynamics of the dramatic arc — and therefore the dynamics of the plot—by experiencing emotional rises and falls that move the story forward. Characters in stories, just like people in real life, oscillate between positive and negative reactions to external events (Kahneman, 
M.Sc. Thesis - C. Tu; McMaster University - Psychology, Neuroscience \& Behaviour

Krueger, Schkade, Schwarz, \& Stone, 2004; Watson, 2000). Cinderella has a fall in emotionality from her anxious emotional appraisal towards the triggering situation, which initiates a problemsolving arc that is different from Jack's in Jack and the Beanstalk, who has a rise in emotionality from his desire-based emotional appraisal of the triggering situation. Cinderella has a coping conflict wherein she strives to relieve a negative situation, whereas Jack has a striving conflict wherein he strives to achieve a rewarding outcome. While it can be argued that Cinderella is also striving to attend the ball, she is striving for a sense of equality and agency, which her stepmother has deprived her of. On the other hand, Jack is not struggling against an antagonistic force from the beginning but is seeking to improve his situation. Jack's emotionality continues to rise as he climbs the beanstalk and acts out of curiosity, while Cinderella experiences her first rise in emotion later in the story when her fairy godmother intervenes to provide her with the means of attending the ball. Already, the plots of the two stories take on different emotional shapes. If we compare the emotionality of Appraisal 1 and Decision 1 for the two stories, then Cinderella has a fall-rise shape, whereas Jack has a sustained rise shape. We contend that the EP model will be useful in categorizing plots based on the shape of their emotional dynamics, as seen in previous studies of sentiment analyses of story texts (Reagan et al., 2016). Thus, the EP model has the potential to not only be an analytical tool, but also a story-classification and production tool.

If we had compared these two stories using Propp's (1928/1958) 31 functions or Mandler's (1984) and Rumelhart's (1975) story grammars, then we would not have been able to differentiate between the emotionality of the two protagonists, and we would have therefore not been able to differentiate between their striving and coping conflicts. A role-based plot model, such as the hero's journey, would describe Cinderella and Jack as going through the same 
M.Sc. Thesis - C. Tu; McMaster University - Psychology, Neuroscience \& Behaviour

journey in which they leave home, experience a change, then return home. However, by not specifying the dynamics of the hero's emotionality, the hero's journey is not able to explain how heroes in different stories experience different changes. Vonnegut's (1981) six plot types are able to differentiate stories depending on the dynamics of the rises and falls in a story. However, these rises and falls are not specific to the protagonist's psychology; they refer instead to changes that happen to the protagonist, not the feelings and actions experienced $b y$ the protagonist. For instance, Vonnegut categorizes Cinderella as having a rise-fall-rise plot. However, the EP model diverges from Vonnegut and instead indicates that Cinderella has a fall-rise-fall-rise plot because Cinderella has a negative appraisal of the triggering situation produced by her stepmother (Figure 6). This difference in shape of the plot matters because the EP model emphasizes both the protagonist's initial conflict and the change they undergo. Vonnegut's analysis of Cinderella overlooks the negativity that she experiences at the beginning of the story.

An advantage of the EP model is that it combines two important psychological processes that transcend both narratives and everyday life: emotional appraisals and problem solving. Traditional plot models do not consider how "emotions are typically part of an ongoing dialogue rather than the expression of a soliloquy" (Parkinson \& Manstead, 1993). The experience of emotions is not an isolated event, but is an interactive and emergent experience that affects downstream cognitive processes, as well as the development of interpersonal relationships between characters. Emotions therefore underlie embodiment since they mediate how a character interacts with their situation. Colombetti (2007) and Oatley and Johnson-Laird (1987) argued that emotions are not just side-effects of external disturbances and interruptions, but that they have cognitive functions. Three of the main functions of emotions include narrowing attention, expression through embodied behavior, and stimulation of action tendencies that lead to goal 
M.Sc. Thesis - C. Tu; McMaster University - Psychology, Neuroscience \& Behaviour

resolution (Bagozzi \& Pieters, 1998; Farb, Chatman, \& Anderson, 2013). These emotional functions correspond with the functions of plot in that plot similarly narrows narrative focus, is driven by the intentional actions of the character, and motivates the protagonist to progress towards the resolution of a goal.

There are a number of limitations of the EP model that need to be addressed in future work. The model has only been applied to short fairy tale texts thus far. As such, it has not yet been used to study complex plots, such as the types of stories that are often portrayed in novels, plays, and films that have multiple protagonists, multiple interwoven storylines, non-linear narratives, and emergent narratives (such as in improvisational acting). However, given that the EP model includes core problem-solving components to explain plot progression - such as emotional appraisals, decision making, goal formulation, action planning, and action evaluation - we predict that it can be versatile and effective in modelling complex narratives across different media. This is because the model does not require that the narrative specify the thoughts of the protagonist, but merely their emotions. Palmer (2004) pointed out that "emotions is one of the most obvious ways in which thought can become public" (p. 115). The protagonist's emotionality is therefore one of the most easily accessible cognitive responses that can be inferred by the reader, and it is also the root of the character's decision-making and goalformulation processes (Bechara, Damasio, \& Damasio, 2000; Elster, 1996). Even if a narrative is devoid of mentalistic descriptions of the protagonist's thoughts and beliefs, this would not serve as an obstacle for the EP model. O’Neill (1996:50) argued that a text can reveal a character in two ways: through direct diegetic telling or through indirect mimetic presentation. Mimetic depiction of a character is often found in non-textual media such as film and video games in which expositional action and expression are dominant over diegetic narration. Thus, the EP 
M.Sc. Thesis - C. Tu; McMaster University - Psychology, Neuroscience \& Behaviour

model has the potential to model the emotional rises and falls of protagonists depicted in nontextual media that employ mimetic depictions of characters, in which complex narratives are also commonly found. Moreover, Bortolussi (2011) criticized Palmer's emphasis on the fictional mind and argued that "characters do not have theories of minds of other characters; they only think or know what the narrators tell us." It is important to note that while the EP model foregrounds character psychology, the model does not attempt to model fictional thought or consciousness. Rather, the aim of the EP model is to map how key embodied psychological processes involved in the protagonist's problem-solving episodes construct the dynamics of plot structure. Mentalistic descriptions of thoughts and beliefs are helpful, but are in no way necessary to the model.

The EP model does not currently consider protagonist personality or antagonist personality. The aim of the EP model is to explain how the protagonist's problem-solving arc drives plot progression, and so the model is focused on the protagonist's "state" features - which are their transient and causally-linked cognitive processes - rather than their enduring "trait" features. However, we recognize that problem-solving strategies will vary between different people (Heppner \& Krauskopf, 1987). Individual factors such as age, gender, culture, and socioeconomic status will influence problem-solving strategies. People do not fit into a single type of problem-solving arc, which is determined by the idiosyncrasies of an individual. In addition, we suggest that these are important factors that should be considered in terms of how they affect the protagonist's relationship with the antagonist. The pairing of different traits will create different relationships and therefore different conflicts, which we described in Appraisal 1. The pairing of an assertive protagonist with an aggressive antagonist may create a striving conflict, such as Jack and the ogre in Jack and the Beanstalk, while the pairing of a non-assertive 
M.Sc. Thesis - C. Tu; McMaster University - Psychology, Neuroscience \& Behaviour

protagonist with an oppressive antagonist may create a coping conflict, such as Cinderella and her stepmother.

Another limitation of the EP model is that it may not adequately describe episodes in which the protagonist is absent or those in which the narrative is focused on another character. Currently, the EP model relegates non-protagonist-based episodes to Component 14 (Intervention Action or Destruction). We believe that this is sufficient for fairy tales, given that most stories focus on a single protagonist, and that any discussion of other characters is usually set in relation to the protagonist (Magliano, Taylor, \& Kim, 2005). However, in complex narratives, such as those in which the primary antagonist is a prominent character and has an elaborate backstory, there may be episodes that are entirely focused on that character, and the EP model does not currently account for this. A possible approach to addressing this issue would be to expand the EP model to include multiple interacting character timelines for large-scale and complex narratives. All in all, while the EP model is still in its preliminary stages, it has the potential to develop into a nuanced plot model that can be used for story analysis across a broad spectrum of narrative media and formats.

\section{Conclusions}

The Embodied Plot model presents a new approach to understanding the nature of plot, one in which the progression of a plot is not only character-driven, but character-embodied. The model segregates a story's components into two realms: the storyworld and protagonist psychology, the latter of which makes up the embodied component of the model. Protagonist psychology is driven by an overarching problem-solving cycle for the protagonist, whereby causally-linked psychological processes related to emotional appraisal, motivation/intentionality, 
M.Sc. Thesis - C. Tu; McMaster University - Psychology, Neuroscience \& Behaviour

decision making, goal formulation, agency, and action planning propel the protagonist to engage in goal-directed actions and overcome obstacles. The central tenet of the model is that the dramatic arc of a story maps onto the rises and falls in the emotions of the protagonist. In other words, plot structure is isomorphic with the psychological experience of the protagonist inside the storyworld, most especially the character's problem-solving dynamics. We applied the model to the analysis of a small number of folk tales. However, the model has the potential to explain large-scale plots, such as those of novels and films, as well as emergent plots, such as those found in improvisational acting and certain types of video games.

\section{Acknowledgments}

This work was funded by a grant from the Social Sciences and Humanities Research Council (SSHRC) of Canada to Dr. Steven Brown. We thank Terence Patrick Murphy and Marco Caracciolo for critical reading of the manuscript. We thank Talysha Bujold-Abu for creating the two comics in Figure 1. 
M.Sc. Thesis - C. Tu; McMaster University - Psychology, Neuroscience \& Behaviour

\section{References}

Abbott, H. P. (2008). The Cambridge introduction to narrative. $2^{\text {nd }}$ ed. Cambridge, UK: Cambridge University Press.

Aristotle (335 BCE/1996). Poetics. London, UK: Penguin Books.

Austin, J. T., \& Vancouver, J. B. (1996). Goal constructs in psychology: Structure, process, and content. Psychological Bulletin, 120(3), 338.

Bal, M., \& van Boheemen, C. (2017). Narratology: Introduction to the theory of narrative. $4^{\text {th }}$ ed. Toronto: University of Toronto Press.

Bagozzi, R. P., \& Pieters, R. (1998). Goal-directed emotions. Cognition \& Emotion, 12(1), 1-26.

Bietti, L. M., Tilston, O., \& Bangerter, A. (2018). Storytelling as adaptive collective sensemaking. Topics in Cognitive Science, 1-23.

Black, J. B., \& Bower, G. H. (1980). Story understanding as problem-solving. Poetics, 9(1-3), 223-250.

Bolens, G. (2012). The style of gestures: Embodiment and cognition in literary narrative. Baltimore: John Hopkins University Press.

Booker, C. (2004). The seven basic plots: Why we tell stories. New York: Continuum.

Bortolussi, M. (2011). Response to Alan Palmer's "Social minds". Style, 45(2), 283-287.

Bower, G. H. (1976). Experiments on story understanding and recall. Quarterly Journal of Experimental Psychology, 28(4), 511-534.

Boyd, B. (2009). On the origin of stories: Evolution, cognition, and fiction. Cambridge, MA: Harvard University Press.

Brown, S., Berry, M., Dawes, E., Hughes, A., \& Tu, C. (2019). Character mediation of story generation via protagonist insertion. Journal of Cognitive Psychology, 31(3), 326-342. 
M.Sc. Thesis - C. Tu; McMaster University - Psychology, Neuroscience \& Behaviour

Bruner, J. (1986). Actual minds, possible worlds. Cambridge, MA: Harvard University Press.

Butler, L., \& Meichenbaum, D. (1981). The assessment of interpersonal problem-solving skills. In n P. C. Kendall \& S. D. Hollon (Eds.), Assessment strategies for cognitive-behavioral interventions (pp. 197-225). New York: Academic Press.

Caracciolo, M. (2012). Fictional consciousnesses: A reader's manual. Style, 46(1), 42-65.

Caracciolo, M. (2014). Tell-tale rhythms: Embodiment and narrative discourse. Storyworlds, 6(2), 49-73.

Carver, C. S., \& Scheier, M. F. (1990). Origins and functions of positive and negative affect: a control-process view. Psychological Review, 97(1), 19.

Carver, C. S., \& Scheier, M. F. (2001). On the self-regulation of behavior. Cambridge, UK: Cambridge University Press.

Chatman, S. (1990). What can we learn from contextualist narratology? Poetics Today, 11(2), 309328.

Coello, Y., \& Fischer, M. H. (Eds.). (2016). Foundations of embodied cognition: Perceptual and emotional embodiment. New York: Routledge.

Cohn, N. (2013). Visual narrative structure. Cognitive Science, 34, 413-452

Colombetti, G. (2007). Enactive appraisal. Phenomenology and the Cognitive Sciences, 6(4), 527546.

Culler, J. (1980). Fabula and sjuzhet in the analysis of narrative: Some American discussions. Poetics Today, 1(3), 27-37.

Bechara, A., Damasio, H., \& Damasio, A. R. (2000). Emotion, decision making and the orbitofrontal cortex. Cerebral Cortex, 10(3), 295-307. 
M.Sc. Thesis - C. Tu; McMaster University - Psychology, Neuroscience \& Behaviour

De Fina, A., \& Georgakopoulou, A. (2012). Analyzing narrative: Discourse and sociolinguistic perspectives. Cambridge, UK: Cambridge University Press.

Eder, J., Jannidis, F., \& Schneider, R. (Eds.). (2010). Characters in fictional worlds: Understanding imaginary beings in literature, film, and other media. Berlin: Walter de Gruyter.

Elster, J. (1996). Rationality and the emotions. The Economic Journal, 106(438), 1386-1397.

Farb, N. A., Chapman, H. A., \& Anderson, A. K. (2013). Emotions: Form follows function. Current Opinion in Neurobiology, 23(3), 393-398.

Fludernik, M. (1996). Towards a "natural” narratology. London, UK: Routledge.

Förster, J., Grant, H., Idson, L. C., \& Higgins, E. T. (2001). Success/failure feedback, expectancies, and approach/avoidance motivation: How regulatory focus moderates classic relations. Journal of Experimental Social Psychology, 37(3), 253-260.

Fox, S., \& Hoffman, M. (2002). Escalation behavior as a specific case of goal-directed activity: A persistence paradigm. Basic and Applied Social Psychology, 24(4), 273-285.

French, E. G., \& Thomas, F. H. (1958). The relation of achievement motivation to problem-solving effectiveness. Journal of Abnormal and Social Psychology, 56(1), 45.

Friedman, N. (1955). Forms of the plot. Journal of General Education, 8(4), 241-253.

Gabriel, Y. (2000). Storytelling in organizations: Facts, fictions, and fantasies. Oxford, UK: Oxford University Press.

Gallagher, S. (2000). Philosophical conceptions of the self: implications for cognitive science. Trends in Cognitive Sciences, 4(1), 14-21.

Genette, G. (1982). Frontiers of narrative. Figures of Literary Discourse, 127-144.

Genette, G. (1988). Narrative discourse revisited. Ithaca, NY: Cornell University Press. 
M.Sc. Thesis - C. Tu; McMaster University - Psychology, Neuroscience \& Behaviour

Goldinger, S. D., Papesh, M. H., Barnhart, A. S., Hansen, W. A., \& Hout, M. C. (2016). The poverty of embodied cognition. Psychonomic Bulletin and Review, 23, 959-978.

Graesser, A. C., Robertson, S. P., Lovelace, E. R., \& Swinehart, D. M. (1980). Answers to whyquestions expose the organization of story plot and predict recall of actions. Journal of Verbal Learning and Verbal Behavior, 19(1), 110-119.

Habermas, T., Meier, M., \& Mukhtar, B. (2009). Are specific emotions narrated differently? Emotion, 9(6), 751-762.

Haggard, P. (2017). Sense of agency in the human brain. Nature Reviews Neuroscience, 18, $197-$ 208.

Heckhausen, H., \& Gollwitzer, P. M. (1987). Thought contents and cognitive functioning in motivational versus volitional states of mind. Motivation and Emotion, 11(2), 101-120.

Heppner, P. P., \& Krauskopf, C. J. (1987). An information-processing approach to personal problem solving. The Counseling Psychologist, 15(3), 371-447.

Heppner, P. P., Witty, T. E., \& Dixon, W. A. (2004). Problem-solving appraisal and human adjustment: A review of 20 years of research using the Problem Solving Inventory. The Counseling Psychologist, 32(3), 344-428.

Herman, D. (2004). Story logic: Problems and possibilities of narrative. Lincoln: University of Nebraska Press.

Herman, D. (2013). Storytelling and the sciences of mind. Cambridge, MA: MIT Press.

Herman, L., \& Vervaeck, B. (2005). Handbook of narrative analysis. Lincoln: University of Nebraska Press. 
M.Sc. Thesis - C. Tu; McMaster University - Psychology, Neuroscience \& Behaviour

Higgins, E. T., Shah, J., \& Friedman, R. (1997). Emotional responses to goal attainment: strength of regulatory focus as moderator. Journal of Personality and Social Psychology, 72(3), 515525.

Hogan, P. C. (2013). How authors' minds make stories. Cambridge, UK: Cambridge University Press.

Jacobs, J. (1890). Jack and the beanstalk. In English fairy tales (pp. 59-67). London, UK: David Nutt.

Jacobs, J. (1890). Tom Tit Tot. In English fairy tales (pp. 3-8). London, UK: David Nutt.

Kahneman, D., Krueger, A. B., Schkade, D. A., Schwarz, N., \& Stone, A. A. (2004). A survey method for characterizing daily life experience: The day reconstruction method. Science, 306(5702), 1776-1780.

Kahneman, D., Slovic, S. P., Slovic, P., \& Tversky, A. (Eds.). (1982). Judgment under uncertainty: Heuristics and biases. Cambridge, UK: Cambridge University Press.

Keen, S. (2006). A theory of narrative empathy. Narrative, 14(3), 207-236.

Kemdal, A. B., \& Montgomery, H. (2002). Perspectives and emotions in personal decision making. In R. Crozier, R. Ranyard, \& O. Svenson (Eds.), Decision making (pp. 86-103). London, UK: Routledge.

Klein, G. (2008). Naturalistic decision making. Human Factors, 50(3), 456-460.

Kuzmičová, A. (2014). Literary narrative and mental imagery: A view from embodied cognition. Style, 48(3), 275-293.

László, J. (2008). The science of stories: An introduction to narrative psychology. New York: Routledge. 
M.Sc. Thesis - C. Tu; McMaster University - Psychology, Neuroscience \& Behaviour

Lazarus, R. S. (1968). Emotions and adaptation: Conceptual and empirical relations. In W. J. Arnold (Ed.), Nebraska symposium on motivation. Lincoln: University of Nebraska Press.

Lehr, F. (1987). ERIC/RCS: Story grammar. Reading Teacher, 40(6), 550-52.

Locke, E. A. (1996). Motivation through conscious goal setting. Applied and Preventive Psychology, 5(2), 117-124.

Lebreton, M., Abitbol, R., Daunizeau, J., \& Pessiglione, M. (2015). Automatic integration of confidence in the brain valuation signal. Nature Neuroscience, 18(8), 1159-1167.

Lee, F. (1997). When the going gets tough, do the tough ask for help? Help seeking and power motivation in organizations. Organizational Behavior and Human Decision Processes, $72(3), 336-363$.

Lipshitz, R., Klein, G., Orasanu, J., \& Salas, E. (2001). Taking stock of naturalistic decision making. Journal of Behavioral Decision Making, 14(5), 331-352.

Lopes, M. P., \& Cunha, M. P. E. (2008). Who is more proactive, the optimist or the pessimist? Exploring the role of hope as a moderator. Journal of Positive Psychology, 3(2), 100-109.

Mace, M.-A., \& Ward, T. (2002). Modeling the creative process: A grounded theory analysis of creativity in the domain of art making. Creativity Research Journal, 14, 179-192.

Maiese, M. (2014). Body and emotion. In L. Shapiro (Ed.), The Routledge handbook of embodied cognition (pp. 231-239). New York: Routledge.

Magliano, J. P., Taylor, H. A., \& Kim, H. J. J. (2005). When goals collide: Monitoring the goals of multiple characters. Memory \& Cognition, 33(8), 1357-1367.

Mandler, J. M. (1984). Stories, scripts, and scenes: Aspects of schema theory. New York: Psychology Press. 
M.Sc. Thesis - C. Tu; McMaster University - Psychology, Neuroscience \& Behaviour

Mandler, J. M., \& Goodman, M. S. (1982). On the psychological validity of story structure. Journal of Verbal Learning and Verbal Behavior, 21, 507-523.

Mandler, J. M., \& Johnson, N. S. (1977). Remembrance of things parsed: Story structure and recall. Cognitive Psychology, 9, 111-151.

Mar, R. A., \& Oatley, K. (2008). The function of fiction is the abstraction and simulation of social experience. Perspectives on Psychological Science, 3, 173-192.

Mar, R. A., Oatley, K., Djikic, M., \& Mullin, J. (2010). Emotion and narrative fiction: Interactive influences before, during, and after reading. Cognition \& emotion, 25(5), 818-833.

Marsiske, M., \& Margrett, J. A. (2006). Everyday problem solving and decision making. In J. E. Birren \& K. W. Schaie (Eds.), Handbook of the psychology of aging $6^{\text {th }}$ ed. (pp. 315-342). Burlington, MA: Elsevier Academic Press.

Maslow, A. H. (1943). A theory of human motivation. Psychological Review, 50(4), 370-396.

Mayer, R. E. (1998). Cognitive, metacognitive, and motivational aspects of problem solving. Instructional Science, 26(1-2), 49-63.

Mosier, K. L., \& Fischer, U. (2010). The role of affect in naturalistic decision making. Journal of Cognitive Engineering and Decision Making, 4(3), 240-255.

Murphy, T. P. (2015). The fairytale and plot structure. New York: Palgrave Macmillan.

Nelson-Le Gall, S. (1981). Help-seeking: An understudied problem-solving skill in children. Developmental Review, 1(3), 224-246.

Nuttin, J. (2014). Future time perspective and motivation: Theory and research method. New York: Psychology Press.

Oatley, K. (1999). Why fiction may be twice as true as fact: Fiction as cognitive and emotional simulation. Review of General Psychology, 3(2), 101-117. 
M.Sc. Thesis - C. Tu; McMaster University - Psychology, Neuroscience \& Behaviour

Oatley, K., \& Johnson-Laird, P. N. (1987). Towards a cognitive theory of emotions. Cognition and Emotion, 1(1), 29-50.

O'Neill, P. (1996). Fictions of discourse: Reading narrative theory. Toronto: University of Toronto Press.

Ortony, A., Clore, G. L., \& Collins, A. (1988). The cognitive structure of emotions. Cambridge, UK: Cambridge University Press.

Palmer, A. (2002). The construction of fictional minds. Narrative, 10(1), 28-46.

Palmer, A. (2004). Fictional minds. Lincoln: University of Nebraska Press.

Palmer, A. (2010). Social minds in the novel. Columbus: The Ohio State University Press.

Parkinson, B., \& Manstead, A. S. (1993). Making sense of emotion in stories and social life. Cognition \& Emotion, 7(3-4), 295-323.

Perrault, C. (1687/1889). Cinderella. In A. Lang (Ed.), The blue fairy book (pp. 42-46). Champaign III: Project Gutenberg.

Phelan, J. (1987). Character, progression, and the mimetic-didactic distinction. Modern Philology, 84(3), 282-299.

Phelan, J. (2006). Narrative theory, 1966-2006: A narrative. The Nature of Narrative, 40, 1-33. Phelps, E. A. (2009). The study of emotion in neuroeconomics. In P. W. Glimcher, E. Fehr, C. Camerer, \& R. A. Poldrack (Eds.), Neuroeconomics (pp. 233-248). London, UK: Academic Press.

Polti, G. (1924). The thirty-six dramatic situations (trans. Lucile Ray). Franklin, OH: James Knapp Reeve.

Portelli, S. J. (2013). Probabilistic risk, neuroeconomic ambiguity, and Keynesian uncertainty. Journal of Post Keynesian Economics, 36(1), 3-14. 
M.Sc. Thesis - C. Tu; McMaster University - Psychology, Neuroscience \& Behaviour

Prince, G. (1982). Narratology: The form and functioning of narrative. Berlin: Walter de Gruyter.

Propp, V. (1928/1958). Morphology of the folktale. Bloomington, IN: Indiana University Research Center in Anthropology.

Reagan, A. J., Mitchell, L., Kiley, D., Danforth, C. M., \& Dodds, P. S. (2016). The emotional arcs of stories are dominated by six basic shapes. EPJ Data Science, 5(1), 1-12.

Ricoeur, P. (1980). Narrative time. Critical Inquiry, 7(1), 169-190.

Ronen, R. (1990). Paradigm shift in plot models: An outline of the history of narratology. Poetics Today, 11(4), 817-842.

Roseman, I. J. (1991). Appraisal determinants of discrete emotions. Cognition and Emotion, 5, 161-200.

Rumelhart, D. E. (1975). Notes on a schema for stories. In D. G. Bobrow \& A. Collins (Eds.), Representation and understanding (pp. 211-236). New York: Academic Press.

Ryan, M. L. (1991). Possible worlds, artificial intelligence, and narrative theory. Indianapolis: Indiana University Press.

Ryan, M. L. (2007). Toward a definition of narrative. In D. Herman (Ed.), The Cambridge companion to narrative (pp. 22-35). Cambridge, UK: Cambridge University Press.

Schank, R. C., \& Abelson, R. P. (1977). Scripts, plans, goals and understanding. Oxford, UK: Lawrence Erlbaum.

Scheier, M. F., Carver, C. S., \& Bridges, M. W. (1994). Distinguishing optimism from neuroticism (and trait anxiety, self-mastery, and self-esteem): a reevaluation of the Life Orientation Test. Journal of Personality and Social Psychology, 67(6), 1063.

Schmidt, V. L. (2001). 45 master characters: Mythic models for creating original characters. Cincinnati: Writer's Digest Books. 
M.Sc. Thesis - C. Tu; McMaster University - Psychology, Neuroscience \& Behaviour

Schmidt, V. L. (2001). Writer's guide to characterization: Archetypes, heroic journals, and other elements of dynamic character development. Cincinnati: Writer's Digest Books

Segerstrom, S. C., Tsao, J. C., Alden, L. E., \& Craske, M. G. (2000). Worry and rumination: Repetitive thought as a concomitant and predictor of negative mood. Cognitive Therapy and Research, 24(6), 671-688.

Simon, H. A. (1959). Theories of decision-making in economics and behavioral science. The American Economic Review, 49(3), 253-283.

Smith, C. A., \& Kirby, L. D. (2009). Putting appraisal in context: Toward a relational model of appraisal and emotion. Cognition and Emotion, 23(7), 1352-1372.

Stein, N. L., \& Glen, C. G. (1979). An analysis of story comprehension in elementary school children. In R. O. Freedle (ed.) New directions in discourse processing: Vol. 2. Advances in discourse processes (pp. 53-120). Hillsdale, NJ: Erlbaum.

Theune, M., Faas, S., Nijholt, A., \& Heylen, D. (2003). The virtual storyteller: Story creation by intelligent agents. In Proceedings of the Technologies for Interactive Digital Storytelling and Entertainment (TIDSE) Conference: Vol. 204215 (pp. 1-12). Enschede, Netherlands: University of Twente.

Thorndyke, P. W. (1977). Cognitive structures in comprehension and memory of narrative discourse. Cognitive Psychology, 9, 77-110.

Tobias, R. B. (1993). Master plots: And how to build them. Cincinnati, OH: Writer's Digest Books.

Todorov, T. (1971). The 2 principles of narrative. Diacritics, 1, 37-44.

Todorov, T., \& Weinstein, A. (1969). Structural analysis of narrative. NOVEL: A Forum on Fiction, 3(1), 70-76. Duke University Press. 
M.Sc. Thesis - C. Tu; McMaster University - Psychology, Neuroscience \& Behaviour

Trabasso, T., \& Nickels, M. (1992). The development of goal plans of action in the narration of a picture story. Discourse Processes, 15, 249-275.

Trabasso, T., \& Van Den Broek, P. (1985). Causal thinking and the representation of narrative events. Journal of Memory and Language, 24(5), 612-630.

Tversky, A., \& Kahneman, D. (1991). Loss aversion in riskless choice: A reference-dependent model. Quarterly Journal of Economics, 106(4), 1039-1061.

Vallacher, R. R., \& Wegner, D. M. (1989). Levels of personal agency: Individual variation in action identification. Journal of Personality and Social Psychology, 57(4), 660-671.

Van Dijk, T. A. (1976). Philosophy of action and theory of narrative. Poetics, 5(4), 287-338.

Verplanken, B., \& Holland, R. W. (2002). Motivated decision making: Effects of activation and self-centrality of values on choices and behavior. Journal of Personality and Social Psychology, 82(3), 434-447.

Vonnegut, K. (1981). Palm Sunday: An autobiographical collage. New York: Delacorte Press.

Watson, D. (2000). Mood and temperament. New York: Guilford Press.

Weber, E. U., \& Johnson, E. J. (2009). Decisions under uncertainty: Psychological, economic, and neuroeconomic explanations of risk preference. In P. W. Glimcher, E. Fehr, C. Camerer, \& R. A. Poldrack (Eds.), Neuroeconomics (pp. 127-144). London, UK: Academic Press.

Weiland, K. M. (2016). Creating character arcs: The masterful author's guide to uniting story structure, plot, and character development. Plano, TX: PenForASword Publishing.

Wilson, M. (2002). Six views of embodied cognition. Psychonomic Bulletin \& Review, 9(4), 625636. 